\title{
Ultimate Strength Assessment of Steel-Welded Hemispheres under External Hydrostatic Pressure
}

\author{
Sang-Rai Cho ${ }^{1,2}$ - Teguh Muttaqie ${ }^{3,4}$. Seung Hyun Lee ${ }^{5}$ Jaewoo Paek ${ }^{6}$ Jung Min Sohn ${ }^{3,7}$
}

Received: 7 October 2019 / Accepted: 13 May 2020 / Published online: 15 January 2021

(C) The Author(s) 2021

\begin{abstract}
This paper focusses on steel-welded hemispherical shells subjected to external hydrostatic pressure. The experimental and numerical investigations were performed to study their failure behaviour. The model was fabricated from mild steel and made through press forming and welding. We therefore considered the effect of initial shape imperfection, variation of thickness and residual stress obtained from the actual structures. Four hemisphere models designed with R/t from 50 to 130 were tested until failure. Prior to the test, the actual geometric imperfection and shell thickness were carefully measured. The comparisons of available design codes (PD 5500, ABS, DNV-GL) in calculating the collapse pressure were also highlighted against the available published test data on steel-welded hemispheres. Furthermore, the nonlinear FE simulations were also conducted to substantiate the ultimate load capacity and plastic deformation of the models that were tested. Parametric dependence of the level of sphericity, varying thickness and residual welding stresses were also numerically considered in the benchmark studies. The structure behaviour from the experiments was used to verify the numerical analysis. In this work, both collapse pressure and failure mode in the numerical model were consistent with the experimental model.
\end{abstract}

Keywords Steel-welded hemisphere $\cdot$ Collapse pressure $\cdot$ Experiment $\cdot$ Nonlinear FEA $\cdot$ Ultimate strength formulation

\section{Article Highlights}

- Experimental and numerical investigations on welded segment and crown hemisphere were performed.

- Parametric dependence of the level of sphericity, varying thickness and residual welding stresses were also included in the numerical model.

- Accuracy of the predicted design rules was evaluated against the reported test results on the steel-welded model.

- Failure behaviour of the welded test model was investigated.

Jung Min Sohn

jminz@pknu.ac.kr

1 Ulsan Lab, Inc., Ulsan, South Korea

2 School of Naval Architecture and Ocean Engineering, University of Ulsan, Ulsan, South Korea

3 Department of Naval Architecture and Marine Systems Engineering, Pukyong National University, Busan, South Korea

4 Agency for the Assessment and Application of Technology, Center of Technology for Defense and Security Industries - BPPT, Jakarta, Indonesia

5 Hyundai Mipo Dockyard, Ulsan, South Korea

6 Hyundai Heavy Industries, Ulsan, South Korea

7 Interdisciplinary Program of Marine Convergence Design, Pukyong National University, Busan, South Korea

\section{Introduction}

The pressure hull is the most important structural element of submarines and submersibles. These structures must be designed to meet their ultimate strength requirement with a certain safety margin to confirm their desirable diving depth. The spherical form most likely can withstand the highest pressures and widely used in deep manned pressure hulls. The use of titanium spherical hull type was recently considered the most effective in load-carrying capacity in the Hadal zone exploration that reaches to depths of $6000 \mathrm{~m}$ and beyond. These are some success stories in the development of state-of-the-art manned submersible vehicles such as Jiaolong operated by China NDSC (Cui 2018), Shinkai operated by JAMSTEC, Nautile operated by IFREMER, and Consul AS37 operated by Russian Navy (Kohnen 2018). This development of deep manned submersibles represents its important contributions to the ultimate strength of spherical shells. However, on the other point of view, the spherical form is ineffective for managing the internal space arrangement for more complex equipment and those with higher number of crew compared with a cylinder with the same volume space. 
Therefore, ring-stiffened cylinders have been adopted for the main structural form of naval submarines. However, to achieve their optimum design and fulfil the hydrodynamic aspects, those ring-stiffened cylinders are obstructed off by a hemisphere or a torisphere.

The subject of hemispheric shells that can endure the external buckling loads has presented scientific and engineering challenges for more than 100 years (Blachut 2014). Zoelly (1915) derived the first classical buckling theory on spherical form using the relationship between the elasticity modulus, the Poisson ratio of the base material, the radius and the thickness. The theory was based on the assumption of an ideal perfect hemisphere. Thus, the effects of initial shape imperfection, variation of thickness and residual welding stresses have not been considered in the prediction.

Approximately 53 years ago, extensive experimental work was carried out by US Navy at the David Taylor Model Basin (Krenzke and Kiernan 1965; Kiernan and Nishida 1966) and Naval Ship Research and Development Center (Costello and Nishida 1967; Costello 1970) to acquire feasible criteria for the ultimate strength of the fabricated shells. The results show that the deviation of the sphericity, including the thinning due to cold forming, and the presence of the residual welding stress exerted in the fabricated model must be considered to achieve accurate prediction of the ultimate strength. The discrepancy between analytical and experimental data for the deep and shallow spherical shell was also explained by NASA (1969), which gives the recommendation to threat the design buckling pressure as the lower bound of the experimental data.

Galletly et al. (1987) and Galletly and Blachut (1991) then used these evaluations and the reported data as the basis for the further numerical investigation of imperfect steel hemispheres. They found that the lower bound of the US Navy test results can be approximated using polynomial imperfection to determine the required imperfection of the magnitude-to-shell thickness, $\delta / t=0.3$ for $33<R / t<78$ model size. However, the constant value of imperfection magnitude $\delta / t$ will be increased two times for the model over the range of $78<R / t<165$. Shao and Frieze (1989a, b) also determine the collapse load of the hemispheres having asymmetric initial shapes. The testing was then continued by Blachut and Galletly $(1993 ; 1995)$ using near-perfect torisphere and hemisphere to assess the influence of local imperfection. Seven imperfect spun steel hemispheres in the range of $R / t=116$ to 784 have also been examined. Local and global eigenmode imperfection sensitivities were also evaluated through the torispherical, ellipsoidal, and toroidal shell (Blachut and Jaiswal 1999). Evkin and Lykhachova (2017) recommend estimating the design buckling load of spherical shell using the energy perturbation. This design criterion calculated the buckling energy which allows to estimate the perturbation sensitivity and verified through numerical analysis of a spherical shell. An analysis of the imperfection sensitivity of the spherical shell was also conducted by Wagner et al. (2018). They proposed the design procedure that employed the knockdown factor for the collapse predictions of spherical shells. The empirical equation substantiates the initial imperfection that was derived based on the numerical analyses. The demand of the spherical shapes in the engineering application has also triggered the other similar shapes such as torispherical and domes (Blachut et al. 1990, Blachut et al. 1991, Moffat et al. 1992, Blachut 1998) with a variation of height-to-diameter from 0.2 to $1.0, R / t=60$ to 100 , domes for $R / t=100$ (Blachut 2015), bi-segment of an $R / t=94$ spherical shell (Chen et al. 2017) and spherical caps for $R / t=40$ to 125 (Zhang et al. 2018a, b, 2019). An alternative design of the bionic spherical shell, the eggshaped pressure hull, has also numerically and experimentally been studied by Zhang et al. (2017a, b). This research provides a new concept of pressure hull design where it is noted that the egg-shaped pressure hull is less sensitive to geometric imperfection than the conventional spherical shell.

The main goal of the current paper is to assess the reliability of FE analysis for predicting the collapse pressure of the steel-welded hemisphere, thus enabling engineers to use that numerical tool with confidence in determining the capacity in the actual structure case. With that goal in mind, the present study starts with re-running the ultimate strength experiment on the fabricated steel hemisphere under external hydrostatic pressure. In addition, this work is part of the continuous research on pressure hull structures, after the study of the ring-stiffened cylinder (Cho et al. 2018) and the conical shell (Cho et al. 2019). Subsequently, the details of the previous published identical tests on the welded hemisphere and the present fabricated test model on four hemisphere models are briefly summarized in the following section. The details of the present experimental investigation, test procedure and their results are presented in Section 3. Nonlinear FE analyses considering the initial shape of imperfection, varying thickness and residual welding stress were then performed. Before performing the analyses on the present test models, the numerical benchmark on the previous published tests on the near-perfect and fabricated hemisphere was performed in Section 4. The review on the collapse strength code recommendations from Det Norske Veritas, buckling strength analysis (DNV 1995), PD 5500 (PD 5500 2003), Germanischer Lloyd, naval ship technology (DNV-GL 2015), and American Bureau of Shipping, underwater vehicles, systems and hyperbaric facilities (ABS 2011) are provided in Section 5. The discussion is provided in Section 6, and conclusions are described in Section 7. 


\section{Welded Segment and Crown Hemisphere Test Model}

\subsection{Review of Previous Work}

The collapse strength of the hemisphere is greatly influenced by its geometrical and structural imperfection. Therefore, a series of hydrostatic pressure tests on welded hemispheres at US Navy DTMB was conducted to determine the reason behind the gap between the spherical shell as assumed in theory and the practical fabricated spherical shell. Figure 1 shows the schematic of the reference model test (Kiernan and Nishida 1966; Costello and Nishida 1967; Costello 1970).

Forty-one HY-80 steel hemispheres were made using the pressing and welding procedures. The model consists of six individual segments at each 60 degrees, closed by a spherical cap. The stress-relieving treatments were applied to some models in a hot furnace at $552{ }^{\circ} \mathrm{C}\left(1025^{\circ} \mathrm{F}\right)$ for $1 \mathrm{~h}$. Some of the models were left in as-welded condition, so the effect of stress relief can be quantified. Prior to testing, each hemisphere was welded to the ring-stiffened cylinder mode. The plate thickness of the cylindrical shell was increased more than $10 \%$ compared with hemispherical shell thickness to provide the membrane conditions at the juncture of hemisphere and cylinder. The details of the geometrical range for the reference and the present test model are shown in Table 1.

\subsection{Present Test Model}

Four models, HS-1 to HS-4, were made using petal welding procedures, the same method as that used for fabricating the actual full-size submarine end closures. Residual stresses and imperfections were induced in the model, as the method uses pressing and welding processes. First, each piece of spherical shell was individually cold-
Table 1 Summary of the geometrical and material properties of available tests on welded hemisphere

\begin{tabular}{|c|c|c|c|c|}
\hline \multirow[t]{2}{*}{ Reference } & \multicolumn{2}{|c|}{ Number of data } & \multirow[t]{2}{*}{$R / t$} & \multirow[t]{2}{*}{$E / \sigma_{Y}$} \\
\hline & As-welded & Stress-relieved & & \\
\hline $\begin{array}{l}\text { Kiernan and Nishida } \\
\text { (1966) }\end{array}$ & 12 & 12 & $53 \sim 169$ & $270 \sim 370$ \\
\hline $\begin{array}{l}\text { Costello and Nishida } \\
\text { (1967) }\end{array}$ & 4 & 4 & $34 \sim 41$ & $324 \sim 343$ \\
\hline Costello (1970) & 3 & 6 & $46 \sim 133$ & $310 \sim 335$ \\
\hline $\begin{array}{l}\text { Present study } \\
\text { Total }\end{array}$ & $\begin{array}{l}4 \\
23\end{array}$ & $\overline{22}$ & $\begin{array}{l}87 \sim 133 \\
32 \sim 170\end{array}$ & $\begin{array}{l}632 \sim 727 \\
260 \sim 727\end{array}$ \\
\hline
\end{tabular}

Notes: $R$ is the mean radius, $t$ the thickness, $E$ Young's modulus, and $\sigma_{Y}$ the yield strength

pressed into the desired sphericity. In this case, the cold forming was repeatedly performed until the required overbend curvature was achieved. This process was chosen because the spherical plate could become elastic and springback in the opposite direction. However, this deforming process needs to be closely monitored. After this process was done, then each of those bent plates was welded together. To maintain the sphericity, in the first arrangement, the 60-degree-crown and one of the segment plate sections were welded. Subsequently, the rest of the plates were welded. The detail measurement of the initial geometry imperfection and the variation of shell thickness were measured after all of the fabrication stages were done. All of the tested models were made by using butt joints and single bevel weld-preps. By considering the thicknesses, $4 \mathrm{~mm}$ and $6 \mathrm{~mm}$, the pass sequences were done in two-pass welds. For the sequence with $6 \mathrm{~mm}$ thickness, the pass is approximately $3.2 \mathrm{~mm}$ and $4 \mathrm{~mm}$, whereas for $4 \mathrm{~mm}$ plate thickness, the pass is $2.6 \mathrm{~mm}$ and $3.2 \mathrm{~mm}$. The electrode low hydrogen E 4316 type were used in the welding. The pre- and post-weld procedures are normal of SMAW welding type.

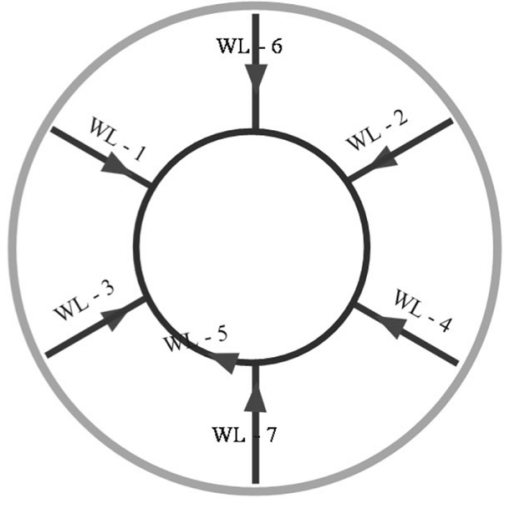

(a) Crown and segments welding hemisphere

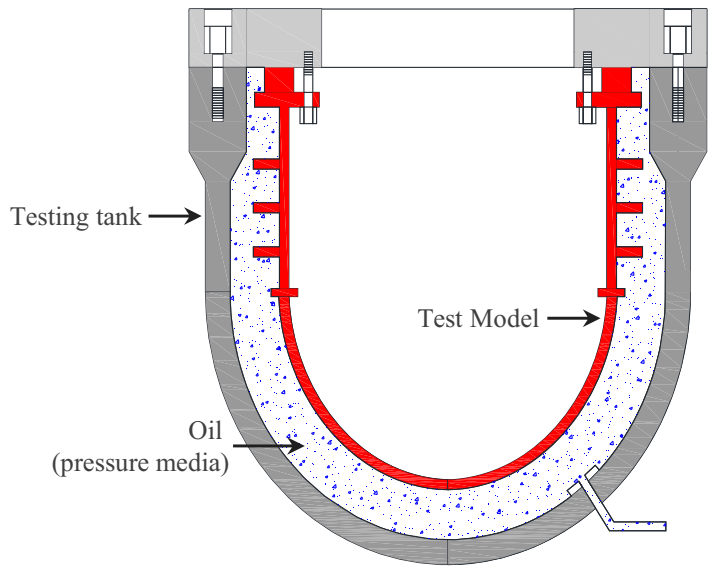

(b) Setup of the external pressure test

Figure 1 Typical fabricated hemisphere model 


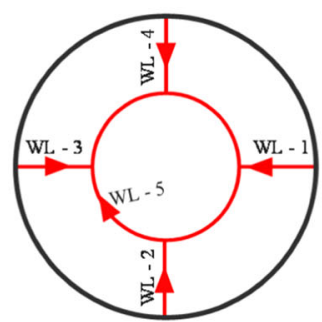

(a)

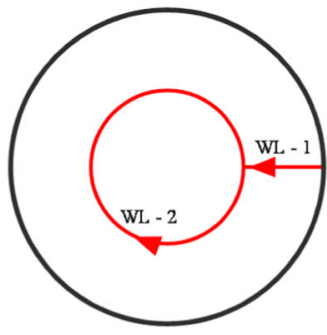

(c)

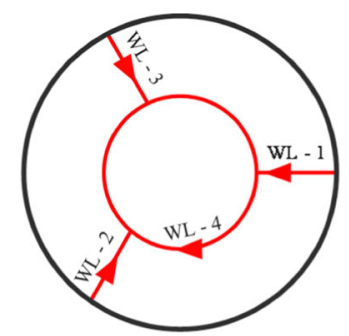

(b)

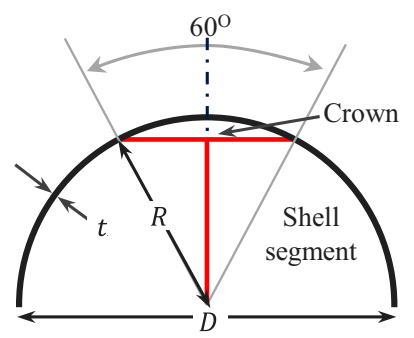

(d)

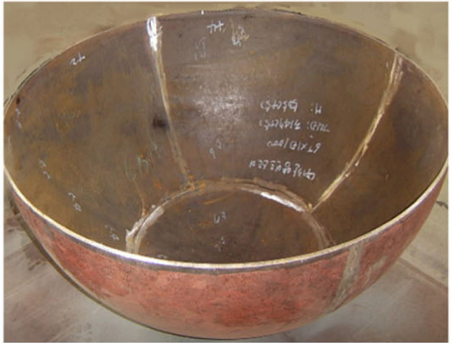

(e)

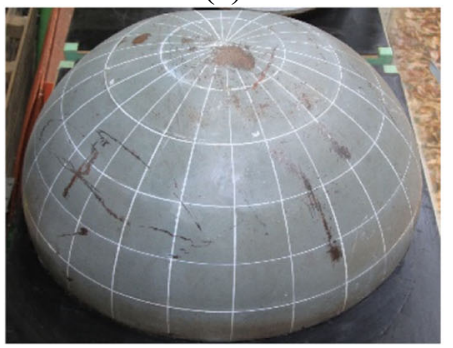

(g)

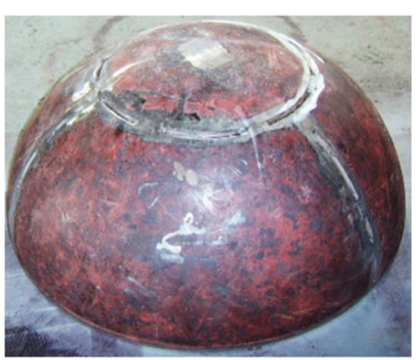

(f)

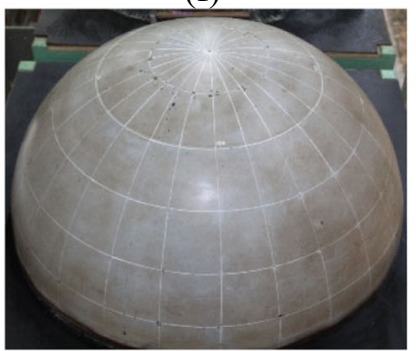

(h)

Figure 2 Welding line: (a) HS-1 and HS-4, (b) HS-2, (c) HS-3, (d) Side view, photograph before painting; (e) HS-1, (f) HS-2, and before testing; (g) HS3 , (h) HS-4

A schematic and photograph of the recent test models are shown in Figure 2. Three types of welding type were investigated in this study. Models HS-1 and HS-4 consist of four segment and one crown. Model HS-2 has three segment and one crown. Finally, a single shell segment was used in model HS-3.

A quasi-static tensile test was performed on coupons cut from the same sheet metal from which the hemispherical shell was fabricated. All of the test models were made from SS41 mild steel. The detail of the dimensions of the recent test hemispheres and the results of the average value from the tensile test are given in Table 2. For all calculations, Young's modulus, $E$, and Poisson's ratio, $\nu$, are fixed at $206000 \mathrm{MPa}$ and 0.3 , respectively. In Figure 3, the engineering stress-strain relation of SS41 material which was adopted in the forthcoming numerical analysis is shown. The yield strength $\sigma_{Y}$ was obtained from $0.2 \%$ offset and in the ranges of $290-332 \mathrm{MPa}$, and ultimate tensile strength, $\sigma_{T}$, is $422-457 \mathrm{MPa}$.

\section{Setup of Experiments}

\subsection{Preparation Before the Test}

Each model was measured for initial imperfections and thickness variations. The measurements were conducted on a custom rotating table (free to rotate) with a dial gauge attached at the arcshaped steel rail. The rail is fixed at the location of the prime meridian of the hemisphere. Thus, the relative distance of the whole direction of the shell can be determined precisely. For the thickness measurement, an ultrasonic gauge was used. The photograph of the device and the typical model measurement in which the model is placed on the turn-table are shown in Figure 4. To support the spatial measurements, the latitude and longitude gridlines were made. The gridlines were drawn at every $15^{\circ}$ interval. The initial shape imperfections and thickness measurements were taken at the cross-point between the axial lines and the radial direction from the outer surface of the shell.

Table 2 Details of the test model parameters

\begin{tabular}{|c|c|c|c|c|c|c|c|c|c|}
\hline \multirow[t]{2}{*}{ Model } & \multicolumn{5}{|c|}{ Shell parameter } & \multicolumn{4}{|l|}{ Material } \\
\hline & $R(\mathrm{~mm})$ & $t(\mathrm{~mm})$ & $S(\mathrm{~mm})$ & $R / t$ & $\lambda$ & $\sigma_{Y}(\mathrm{MPa})$ & $\varepsilon_{Y}$ & $\sigma_{T}(\mathrm{MPa})$ & $E$ \\
\hline HS-1 & 502.9 & 5.75 & 1580 & 87.5 & 20.9 & 290 & 0.001408 & 457 & 206000 \\
\hline HS-2 & 302.9 & 5.72 & 952 & 53.0 & 16.3 & 287 & 0.001393 & 448 & 206000 \\
\hline HS-3 & 501.9 & 3.75 & 1577 & 133.8 & 22.5 & 332 & 0.001612 & 393 & 206000 \\
\hline HS-4 & 577.9 & 5.73 & 1816 & 100.9 & 22.2 & 293 & 0.001422 & 422 & 206000 \\
\hline
\end{tabular}

Notes: $S$ is arc length of the hemisphere (mm), $\lambda$ non-dim parameter, $(S / \sqrt{R t})\left(E / 1000 \sigma_{Y}\right), \sigma_{Y}$ yield strength (MPa), $\varepsilon_{Y}$ yield strain (non-dim), $\sigma_{T}$ tensile strength (MPa), and $E$ Young's modulus (MPa) 


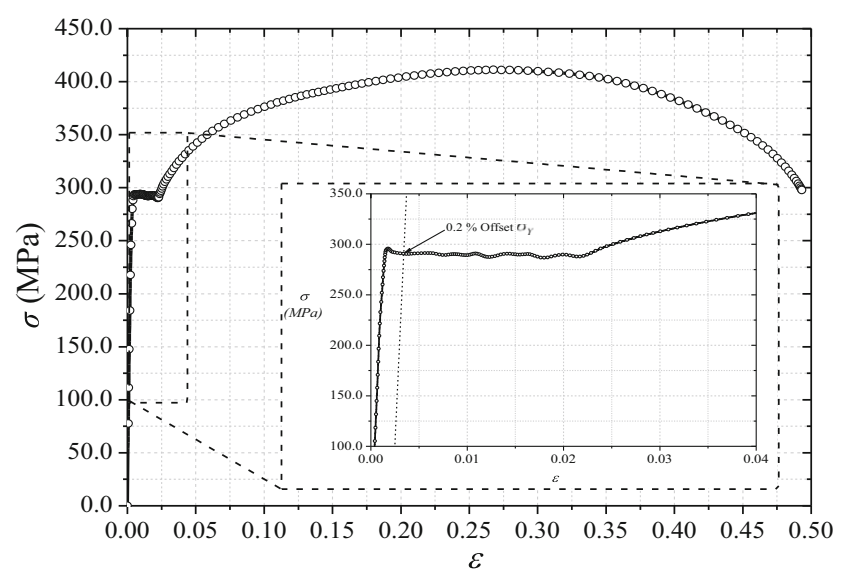

Figure 3 Typical stress-strain curve from the tensile test

By utilizing the result from the dial gauge measurements, the spatial coordinates of the hemispherical shell could be modelled, as seen in Figure 5, for the case of HS-1. To gain a better presentation, the magnitude has been amplified 10 times the original value. The measurement procedures were followed what has been presented in Kendrick (1977). A summary of the imperfection measurements is provided in Table 3. It shows that the amplitude deviate from the mean radius for about $0.90 \%-1.52 \%$ and are inward facing. Since this is a small-scaled model with fabrication treatment as in the actual structure, it is not surprising that the degree of initial imperfection seems greater than what is found in the full-sized structure. Subsequently, the shell thickness measurements were taken by an ultrasonic gauge at the same crossing point of the axial and radial lines in the mid-bay. This measurement resulted in 156-point thickness. The scattering of the shell thickness information of the hemisphere shell model HS-3 is illustrated in Figure 6.

\subsection{Apparatus and Testing}

In performing the test, all the hemisphere models except model HS-2 were pressurized in the pressure chamber with an inner length of $2.8 \mathrm{~m}$ and a diameter of $1.3 \mathrm{~m}$. The maximum chamber pressure can be up to 80 bars. All of the tests and procedures were performed in the Ultimate Limit State ANalysis Laboratory (ULSAN Lab), University of Ulsan. Model HS-2, which was designed to have the highest collapse pressure, was tested using a small-sized chamber with an inner length of $1.8 \mathrm{~m}$ inner length and an inner diameter of $0.65 \mathrm{~m}$. In that case, the chamber is capable of being pressurized up to 120 bars. Figure 7 shows the schematic of the installation of models that were tested in the horizontal-type small and medium size chambers. Since the model volume is relatively large (approximately 18 to $28 \%$ of the chamber volume), the pressure drop evidently occurred immediately after reaching the ultimate strength due to the collapse of the structure (a loud bang was heard in the chamber). That pressure drop phenomenon is different from the actual subsea conditions where the ambient pressure is constant. However, the study is focused on obtaining the ultimate strength and the behaviour under loading. Thus, the pressure drop is neglected.

Initially, before installation into the chamber, the model was welded onto the flange. Then, the O-ring was placed into the groove at the top plane of the flange where special grease is also applied. Finally, the model together with the open flange was lifted and inserted into the chamber and bolted using an air-impact wrench. One active line used for measuring the ambient pressure is located at the top, while another active line, which is used to supply the compressed water, is located at the bottom. The test commenced by increasing the internal pressure up to 2 bars and then depressurising the chamber by opening the release valve. During the test, load increments were uniformly divided into three main runs, the first and second up to approximately $25 \%( \pm 1.5-3$ bars) and approximately $80 \%$ (3-5 bars) of the predicted collapse pressure, and the third was up to the point of collapse with the load at every 0.5 bar. At every pressure increment, the pressure was

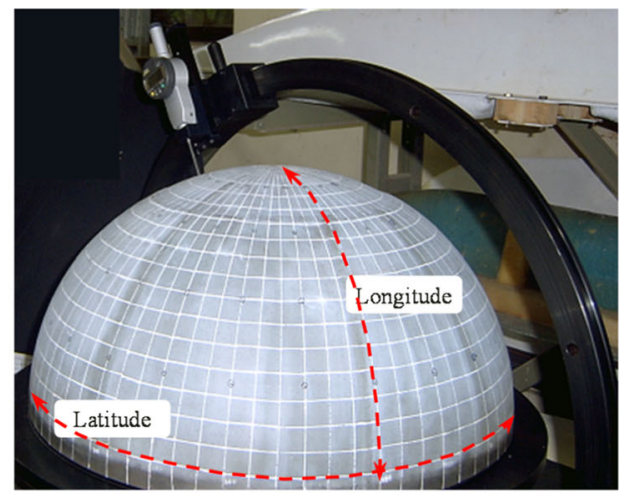

(b) HS-2 sphericity imperfection measurement

Figure 4 Measurement of initial shape imperfection 


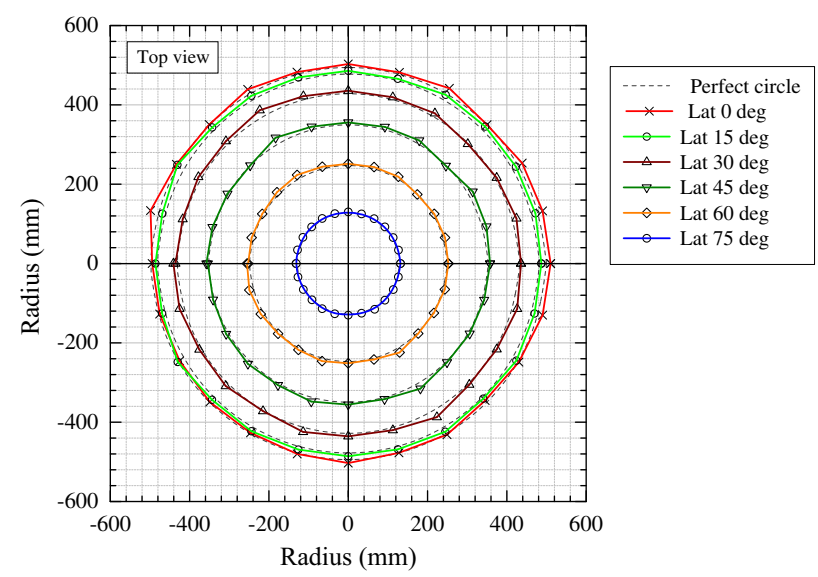

Figure 5 Initial shape imperfection magnified 10 times (HS-1 model)
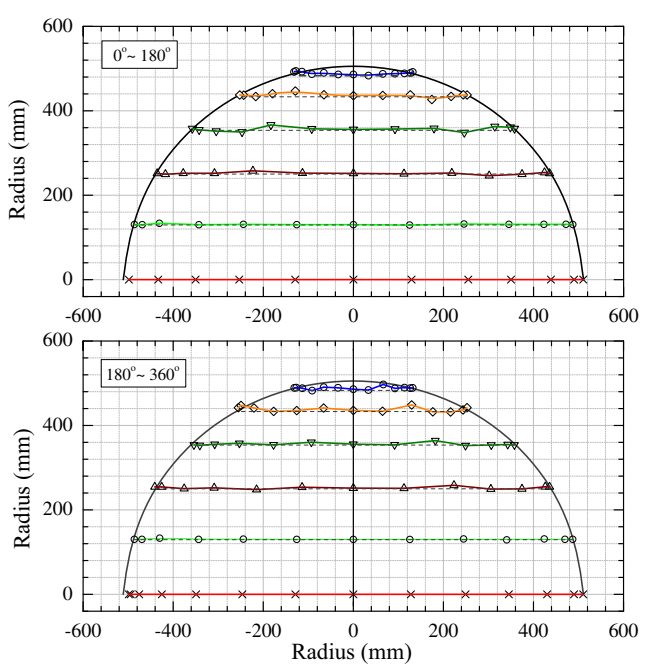

maintained for approximately 0.5 to $1 \mathrm{~min}$ to settle the ambient pressure before increasing further. This procedure was used to model a similar condition where the actual structure gradually submerges in the subsea operation.

The equipment and custom device used during the test are described in Figure 8. The strain gauges were also installed at the inner shell of the model at various locations. All of the hemisphere models were subjected to external hydrostatic pressure up to their failure. During the experiment, visible deformation and other data were recorded to map the trend of plastic deformation to the corresponding area in the shell. In the final stage, after the collapse pressure was reached, the pressure was released gradually, and the water started to drain from the chamber by opening the release valve at the top and bottom of the chamber.

\subsection{Test Results}

\subsubsection{Failure Mode Evaluation}

All hemispheres failed suddenly with an audible sound and a pressure drop recorded immediately after reaching the collapse pressure. Two types of failure mode were observed from the four hemispheres tested. First, the failure occurred starting

Table 3 Details of the imperfection parameter

\begin{tabular}{llllllll}
\hline Model & \multicolumn{3}{l}{ Max. shell out-of-roundness $(\delta)$} & $t_{\min }$ & $\begin{array}{l}t_{\text {avg }} \\
(\mathrm{mm})\end{array}$ & $t_{\max }$ \\
\cline { 2 - 8 } & $\begin{array}{l}\delta / R \\
(\%)\end{array}$ & $\begin{array}{l}R_{\min } \\
(\mathrm{mm})\end{array}$ & $R_{\max }$ & Location & & & \\
\hline HS-1 & 0.90 & 498.32 & 503.48 & Lat $60^{\circ}$, Long 150 & 5.34 & 5.75 & 5.92 \\
HS-2 & 1.52 & 298.25 & 305.55 & Lat $0^{\circ}$, Long 150 & 5.32 & 5.72 & 5.95 \\
HS-3 & 1.14 & 496.13 & 505.67 & Lat $0^{\circ}$, Long 150 & 3.62 & 3.75 & 4.10 \\
HS-4 & 0.78 & 573.34 & 580.46 & Lat $60^{\circ}$, Long 60 & 5.27 & 5.73 & 5.94 \\
\hline
\end{tabular}

from the welding line of the spherical cap and then gradually compressed downward into a local plastic deformation and spread globally. Second, the initial local stress concentration occurred below the crown, near the equator. The plastic deformation started to decelerate along the meridian and terminated at the welding line between the spherical crown and the shell. In the area below the crown, the failure stopped after engaging the end boundary. The experimental collapse pressures and the final deformed configuration of the tested hemisphere are depicted in Figure 9. Based on the post-collapse evidence, we suspect that the number of welding lines (red dotted line) and the size of the hemisphere influenced the failure mode.

Model HS-1 test, which was 500-mm nominal radius and 90 degree weld shell segment, was loaded to a maximum pressure of 5.49 $\mathrm{MPa}$. Receding slightly inward immediately after the ultimate point, water was continuously injected, and the pressure continued to drop to $3.0 \mathrm{MPa}$. The severity of this collapse shape occurred at approximately 270 degrees at the spherical cap involving $2 / 3$ of the hemisphere. In the case of HS-2, a failure mode similar to HS-1 was observed. This model is a 120 degree shell welding line configuration, smaller than HS-1 with a nominal 300-mm radius with the same thickness. The shell moved slightly inward after pressurization, and a maximum pressure of $9.81 \mathrm{MPa}$ was recorded. However, the model resisted a pressure up to $80 \%$ higher than the previous model. After the collapse, the pressure dropped to 5.30 MPa. The centre of the dent was located at the weld line of the crown.

Specimen HS-3 was loaded to collapse and failed at the side shell. Model HS-3 was designed to have the same size sphere radius as HS-1, but the shell thickness was nominally $3.75 \mathrm{~mm}$. The welding configuration had only a single shell segment and its cap. The failure was initiated by yielding of the area 20 degrees above near boundary at 285 degrees longitude. The collapsing walls had grown, covering the area at 

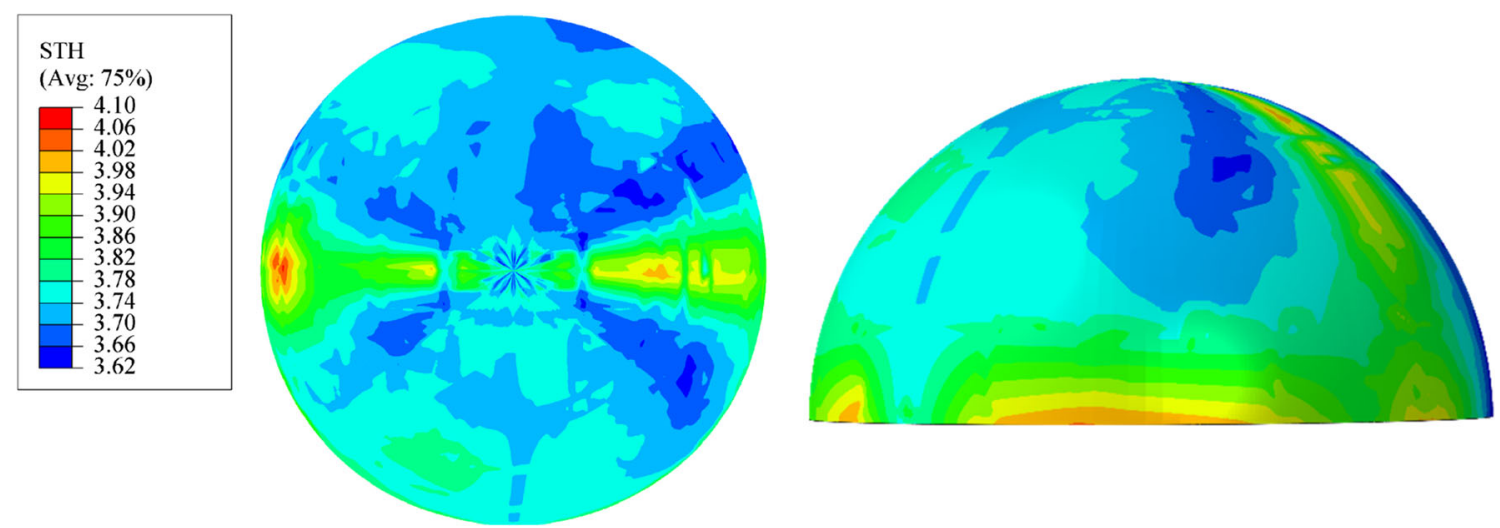

Figure 6 Plotting of thickness variation (HS-3 model)

approximately 45 degrees. The pressure gauge reached a maximum pressure of 3.10 MPa. The last tested model (HS-4) had a configuration similar to HS-1 with a larger diameter. Surprisingly, in this model, the localized plastic deformation followed the HS-3 model at the area below the crown. The crown of inward deformation abruptly stopped when the collapse reached the end boundary and the crown. The computer recorded that this model failed at a pressure of 4.30 MPa.

\subsubsection{Pressure and Strain Evaluation}

In this subsection, two typical types of failure were analysed (i.e. crown failure and shell segment failure). The circumferential strain configuration on the inner side of the hemisphere model of HS-1 (crown failure) plotted against the applied pressure is depicted in Figure 10. A red-filled failure area of each model was noticed. In the case of model HS-1, the crown area experienced compression, where the largest strain was monitored on strain \#4. The tension part was located at the opposite of failure region, showed by strain \#1, \#2 and \#5. The maximum tension strain was found to be about $75 \%$ of yield strain. Thus, from the strain measurement, the location of the first shell yield was expected to be the location of the maximum post-collapse deformation. This location was at approximately $207^{\circ}$ around the welding line of the crown. Once the compressive stress near the welding line reached its yielding stress, the localized plastic deformation penetrated downward to the equator.

Before reaching collapse, model HS-3 began to visibly deform between strain position \#3 and \#8. The deformation showing inward stretching behaviour grew towards the boundary and upward to the crown. Figure 11 shows the response of applied pressure against the strain measurement with their corresponding location. For side shell segment failure, the opposite dent area is in tension. The maximum tension
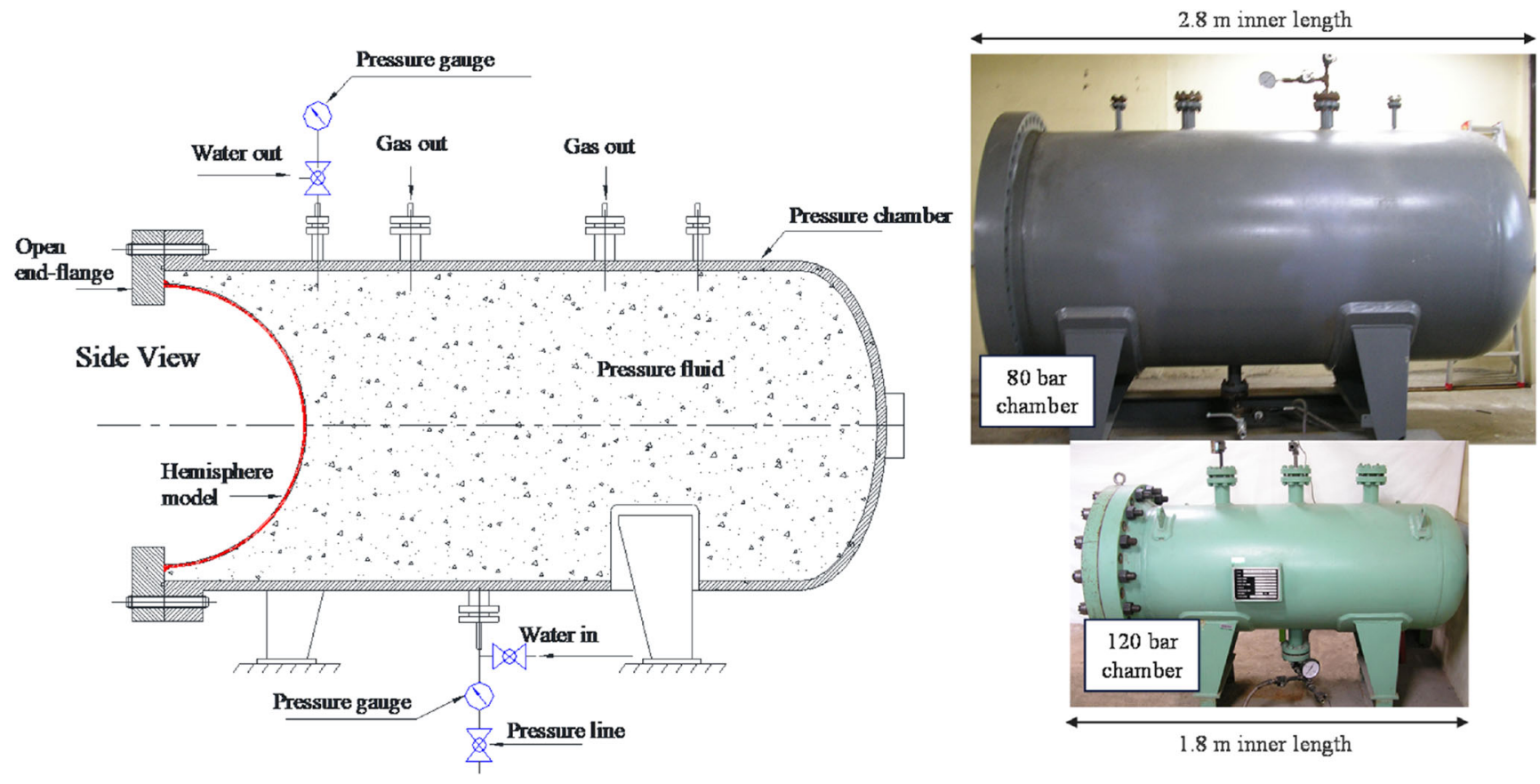

Figure 7 Ultimate strength test setup in the main facility 


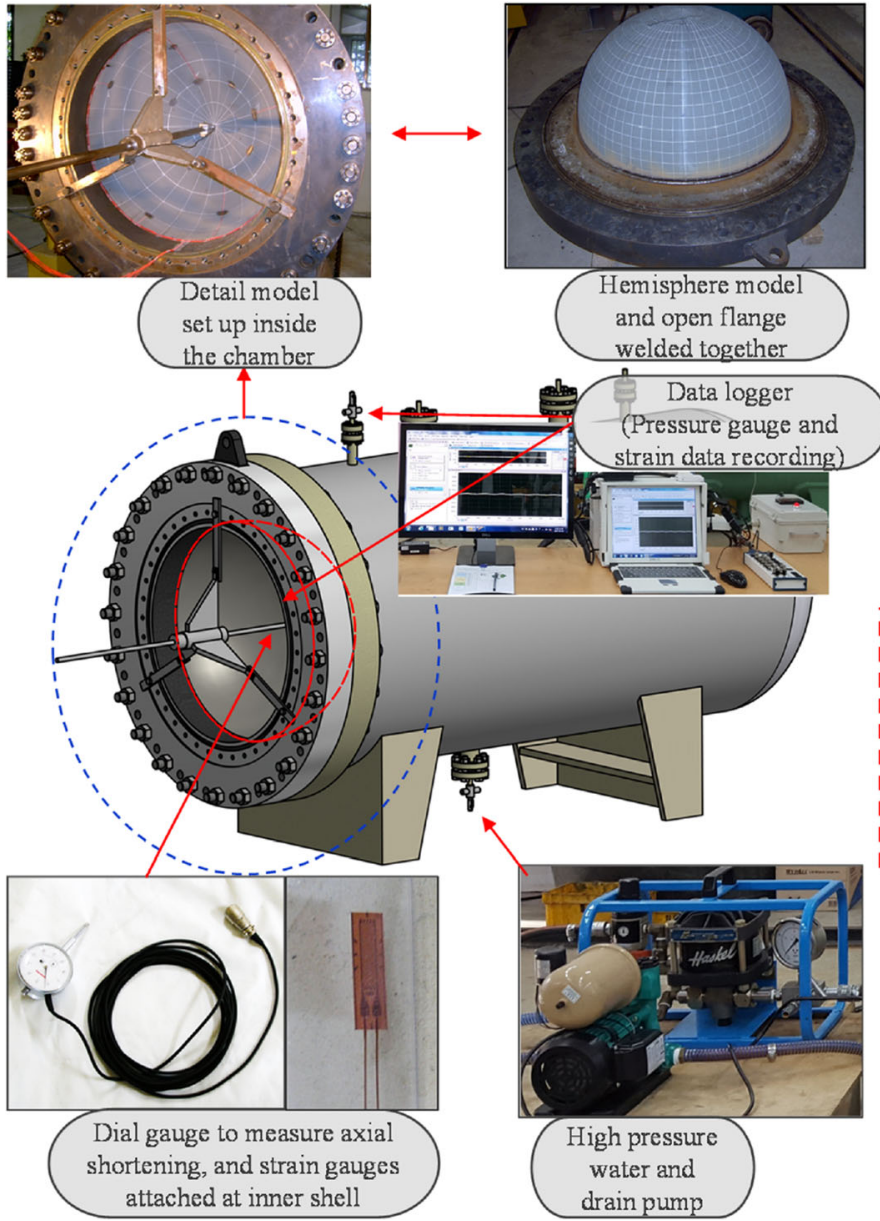

Figure 8 Pre- and post-test procedures of the ultimate strength assessment

strain recorded in position \#4 and \#6 was approximately $66 \%$ of the yield strain.

\section{Numerical Analyses}

In the present study, finite element analyses were performed using a commercial software package Abaqus FEA. The S4R element, which is a 4-node doubly curved finite-strain element with reduced integration and hourglass control, was used for discretization of the physical models. Mesh convergence studies were performed to determine the required mesh density. Pessimistically, the material behaviour was assumed to be elastic-perfect plastic, though this is a reasonable assumption for ultimate strength considerations (Cho et al. 2018, 2019). The shell element also showed good agreement, and computational time can be saved up in the modelling of welding simulation (Shen and Chen 2014). As the solution procedure, a modified Riks method was utilized, which allows both snapback and snap-through to the post-collapse. Initially, to verify the load and boundary conditions, numerical models for symmetrical buckling and for the uppermost of the critical buckling pressures (eigen buckling pressure), the general solution derived by Zoelly (Eq. 1) was used. The results for 50 cases of the numerical hemisphere models that varied in the $R /$ $t$ ratio agree perfectly with the solution as presented in Figure 12. Most of the hemisphere models are numerically tested with the load and BCs of the analyses as presented. Numerical benchmarking was conducted to verify the nonlinear numerical procedures and the validity of the results. Two previous laboratory test models were used as a benchmark. The details of the experiments can be found in Kiernan and Nishida (1966) and Blachut et al. (1990).

$P_{e}=\frac{2 E}{\sqrt{3\left(1-v^{2}\right)}}(t / R)^{2}$

\subsection{Numerical Benchmark on Near-Perfect Hemisphere}

In this benchmark, the machined steel domes were utilized. The models were machined on computer-controlled numerical lathe. Thus, the models achieved a spherical shape which was nearly perfect with no initial radial deviations. The variation of 

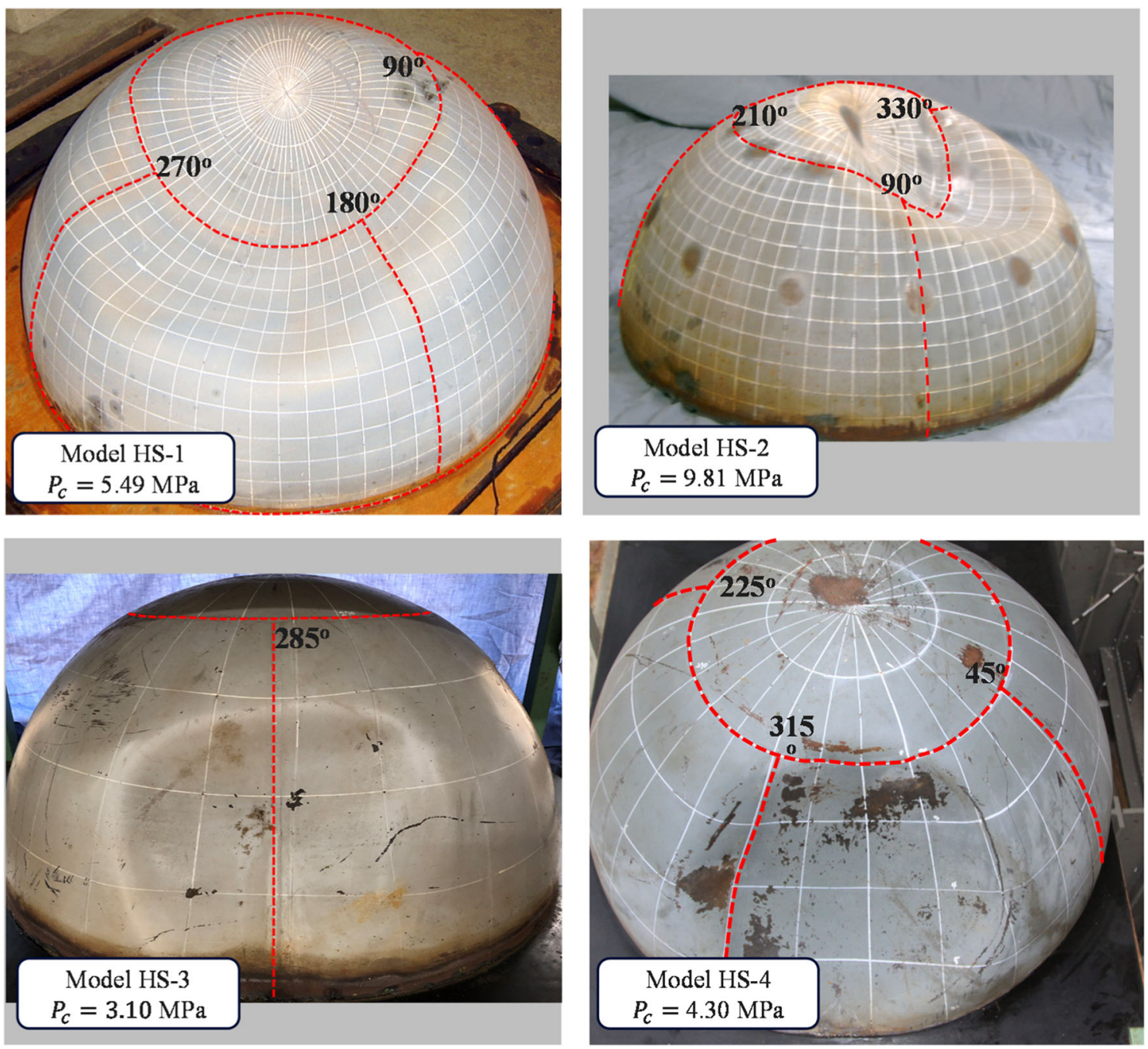

Figure 9 Post-failure shape evaluation for all tested hemisphere model

the shell thickness of the domes differed by almost $4 \%$ from their average thickness. The thickness measurement results along the shell are reported in Table 4. All of the models had a diameter of $0.2 \mathrm{~m}$ and a thickness between 0.653 and
0.775. The variation in thickness shows that the area around the pole is thicker and becomes thinner approaching the equator. This variation is most likely due to the effect of the machined models that were formed from billet mild steel. The
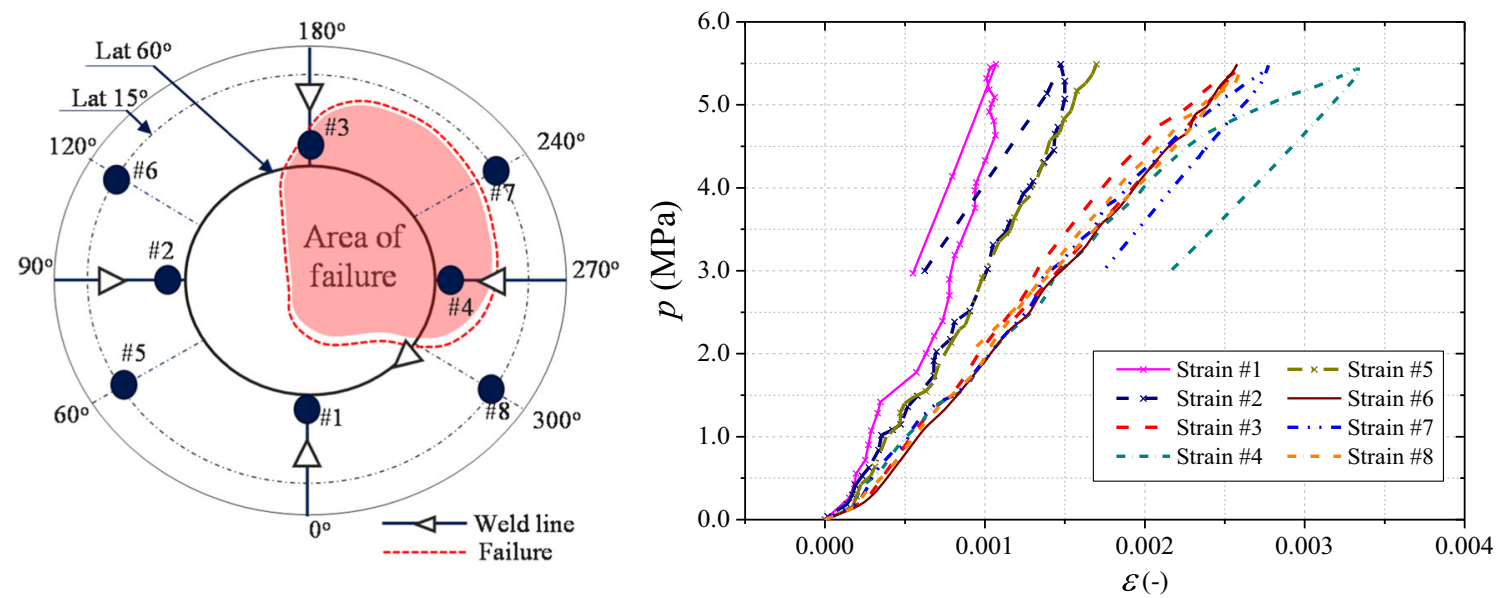

Figure 10 Pressure and strain evaluation model HS-1 (crown failure) 

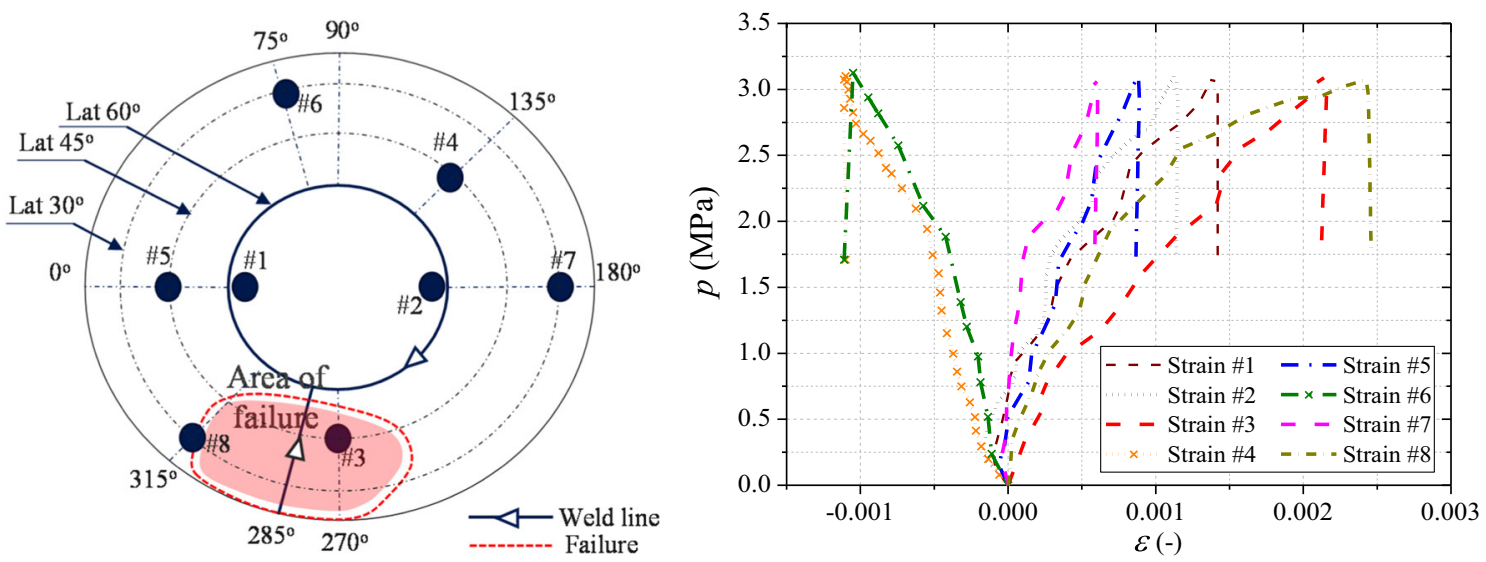

Figure 11 Pressure and strain evaluation of model HS-3 (shell segment failure)

average properties of yield strength $\sigma_{y}$ and the Young's modulus $E$ were determined to be 303.5 and $207000 \mathrm{MPa}$, respectively. In the numerical analyses, the steel was assumed to be elastic and perfectly plastic. As Figure 13 shows, the failure shape between the numerical and the test results was verified. In Table 5, the accuracy of the prediction reached 95\%. The discrepancies among the models are influenced by the variation in their shell thickness. The buckling resistance of the shell was controlled by the height of the sphere $H / D$ ratio, where the weakness was shown by the smallest ratio of $H /$ $D$ (Model 1).

\subsection{Numerical Benchmark on Previous Fabricated Hemisphere}

The detrimental effect of the fabricated hemisphere could be assessed by utilizing the initial shape imperfection, the uneven thickness, and the residual welding stress, and fairly good agreement could be obtained. Yu et al. (2017) simulated the welding process using their thermodynamic properties and revealed that the maximum reduction in ultimate strength is less than $3.25 \%$. Tekgoz et al. (2015) modified the stressstrain curves to introduce the residual stress and showed that

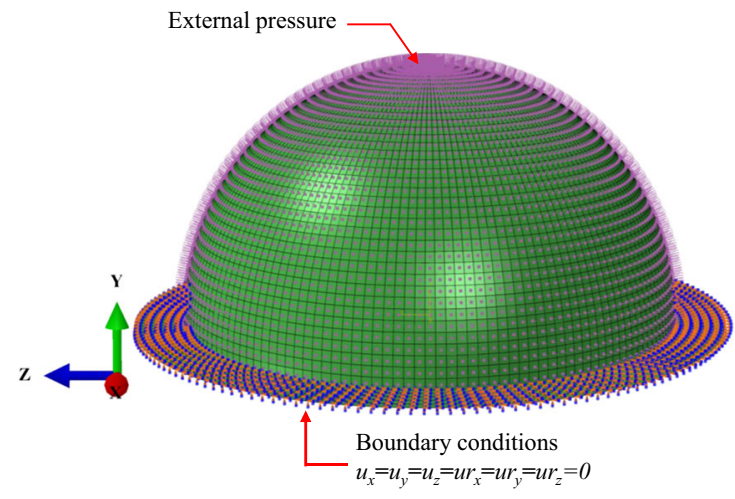

the residual stresses reduce the ultimate load remarkably with thicker plates but have less effect when the plate is thin. To investigate this influencing factor, in this case, fabricated models from Kiernan and Nishida were used. Two pairs of identical models made from HY-80 steel were used. One was the stress-relieved model, and the other was without relieving stress, leaving the welding process as it is. Models 1 and 3 had a diameter of $381 \mathrm{~mm}$, and models 16 and 14 had a diameter of $838.2 \mathrm{~mm}$. In the stress-relieved model, the model was inserted into the hot furnace for $1 \mathrm{~h}$. Then, the model was removed from the furnace and stored at room temperature. By this procedure, the residual welding stress can be diminished. Hence, the buckling resistance was expected to be higher than in the as-welded model. To consider this effect, the weld-line of the hemispherical segment needed to be modelled.

In the numerical analyses, the welding tensile stress was equal to the yield strength of the material. These stresses were established along the welding line, whereas the compressive stress which using an assumption of 0.17 of $\sigma_{Y}$ (Faulkner 1977) was applied at the outside of the weld-lines (across the welding lines). The value of $17 \%$ of yield strength is reasonable involving other parameters such as the initial shape of

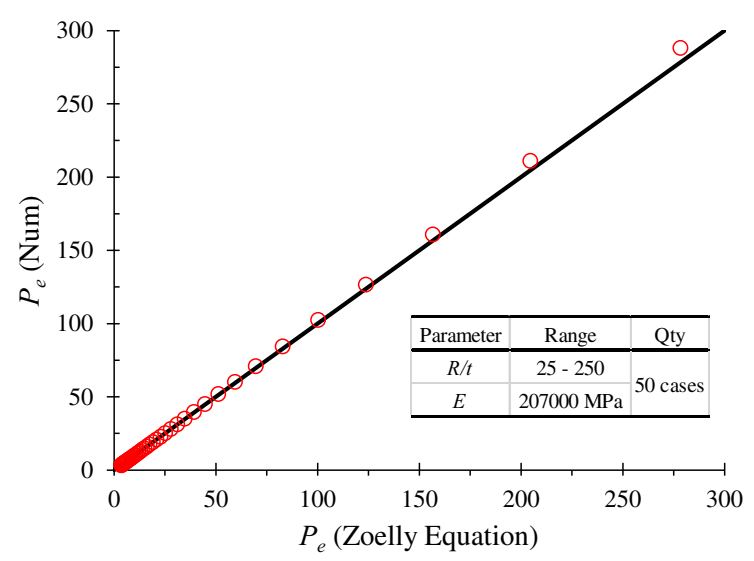

Figure 12 Load and boundary condition for the linear FEA and validation with Zoelly critical pressure 
Table 4 Thickness measurement of the near-perfect test models

Meridian numbers

\begin{tabular}{llllllll}
\hline 1 & 2 & 3 & 4 & 5 & 6 & 7 & 8 \\
\hline 0.667 & 0.667 & 0.667 & 0.667 & 0.667 & 0.667 & 0.667 & 0.667 \\
0.676 & 0.674 & 0.676 & 0.680 & 0.678 & 0.675 & 0.673 & 0.676 \\
0.680 & 0.681 & 0.675 & 0.673 & 0.675 & 0.680 & 0.680 & 0.678 \\
0.674 & 0.674 & 0.668 & 0.663 & 0.671 & 0.674 & 0.674 & 0.676 \\
0.672 & 0.675 & 0.674 & 0.672 & 0.674 & 0.677 & 0.672 & 0.677 \\
0.672 & 0.673 & 0.673 & 0.674 & 0.674 & 0.674 & 0.672 & 0.676 \\
0.672 & 0.673 & 0.671 & 0.671 & 0.671 & 0.672 & 0.672 & 0.670 \\
0.666 & 0.673 & 0.671 & 0.670 & 0.671 & 0.672 & 0.670 & 0.671 \\
0.670 & 0.668 & 0.670 & 0.672 & 0.669 & 0.669 & 0.670 & 0.669 \\
0.670 & 0.672 & 0.672 & 0.672 & 0.673 & 0.673 & 0.671 & 0.673 \\
0.668 & 0.670 & 0.668 & 0.670 & 0.667 & 0.670 & 0.667 & 0.668 \\
0.668 & 0.667 & 0.666 & 0.666 & 0.666 & 0.669 & 0.666 & 0.668 \\
0.663 & 0.665 & 0.664 & 0.663 & 0.664 & 0.663 & 0.665 & 0.669 \\
0.669 & 0.671 & 0.669 & 0.667 & 0.668 & 0.669 & 0.670 & 0.670 \\
0.667 & 0.667 & 0.666 & 0.667 & 0.667 & 0.670 & 0.664 & 0.668 \\
0.661 & 0.663 & 0.660 & 0.664 & 0.657 & 0.663 & 0.663 & 0.662 \\
0.654 & 0.661 & 0.654 & 0.656 & 0.649 & 0.656 & 0.652 & 0.654 \\
\hline
\end{tabular}

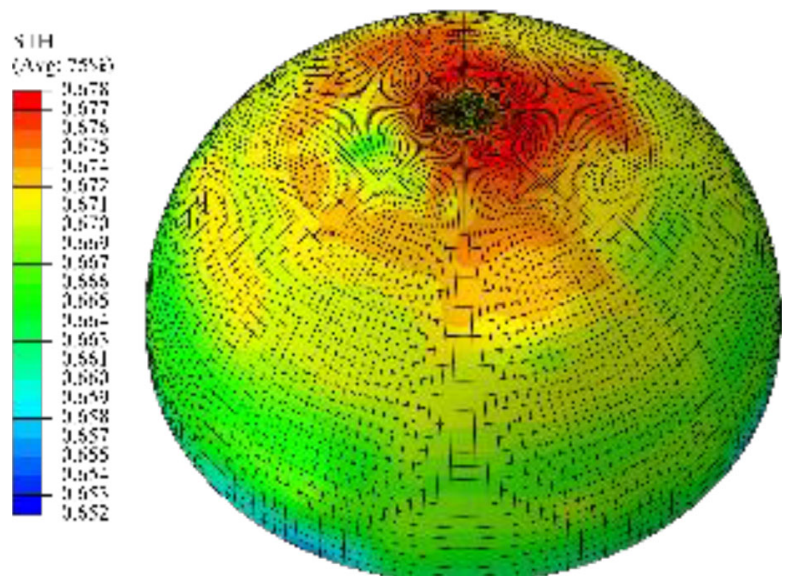

The typical thickness variation on machined model the imperfection and the variation of the thickness. It was determined later that Grunitz (2004) re-tested the flat welded steel in which the effect of initial imperfection and thickness variations were negligible. The specimens of HY-80 material were examined using a neutron strain diffractometer and determined that the compressive strength was $190 \mathrm{MPa}$, which was approximately $30 \%$ of the tensile strength at the weld line.

The results of the numerical analyses of these models are given in Table 6. An equivalent magnitude of imperfection $(\delta)$ from Galletly et al. (1987) was used, assumed to be $\delta / t=0.5$. Both the experimental and the numerically investigated values for the collapse prediction and the failure modes agreed well. In the same table, the ultimate strength of the stress-relieved is approximately 2 to $8 \%$ higher than the as-welded model. In the numerical study, stress-relieved means without residual stress. Overall, the initial imperfection and assumption of the welding residual stress in the numerical analysis procedures give $96 \%$ accuracy for those two kinds of test models.

In Figure 14, the deformed shape is given together with the actual photograph from the test results of the stress- relieved and as-welded (models 1 and 3, respectively). Close agreement was achieved where two models failed at the same location, the failure shape at the $0^{\circ}$ - welding line. To obtain more specific information, the difference in applying the residual stress, the initial loading phase, before and post-collapse are presented in Figure 15. For the as-welded model, as the pressure increases, the residual stress is spread over the shell segment and crown intersection as shown in image Figure 15(a). Before reaching the ultimate state, regions in addition to the welding line receive higher compressive stress. The crown-segment welding intersection can no longer provide support, so the plastic deformation starts to develop, as shown in Figure 15(b). Finally, the local stress concentration at the crown-segment welding intersection promotes a shell failure which reduces the structural strength, and the collapsing wall starts to decelerate approaching the boundary, as shown in Figure 15(c).
Figure 13 Nonlinear FEA benchmark results using nearperfect test models
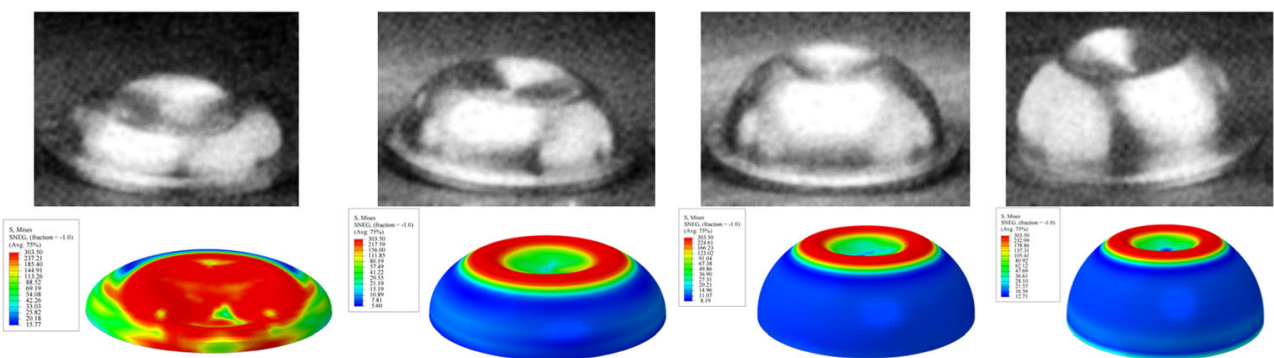

(a)

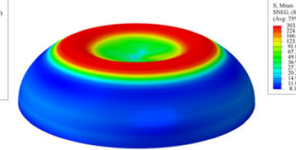

(b)

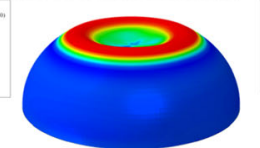

(c)

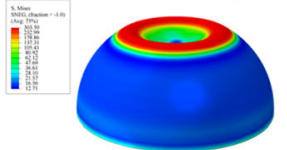

(d) 
Table 5 Nonlinear FEA benchmark accuracy using near-perfect test models

\begin{tabular}{lllll}
$\begin{array}{l}\text { Collapse pressure } \\
\text { (MPa) }\end{array}$ & $\begin{array}{l}\text { Model 4(d) } \\
H / D=0.5\end{array}$ & $\begin{array}{l}\text { Model 3(c) } \\
H / D=0.4\end{array}$ & $\begin{array}{l}\text { Model 2(b) } \\
H / D=0.3\end{array}$ & $\begin{array}{l}\text { Model 1(a) } \\
H / D=0.2\end{array}$ \\
\hline$P_{C, \text { Test }}$ & 3.85 & 1.53 & 1.38 & 1.10 \\
$P_{C, \text { Num }}$ & 3.75 & 1.59 & 1.49 & 1.21 \\
$P_{C, \text { Test }} / P_{C, \text { Num }}$ & 1.02 & 0.97 & 0.92 & 0.91 \\
& $94.61 \%$ Accuracy & & \\
\hline
\end{tabular}

\subsection{Evaluation on Present Test Model}

After the accuracy of the numerical benchmarking was shown, the present test model was analysed. Initially, mesh convergence studies were performed for all the welded models, namely, HS-1 to HS-4. Each mesh was composed of sweep-quad dominated shells with rough mesh at the welding block. Figure 16 shows the results of a convergence study where $6 \mathrm{~mm} \times 6 \mathrm{~mm}$ mesh was chosen for the appropriate size. The ratio $X_{m}$, the eigen buckling pressure and the upper limit elastic buckling pressure from Eq. (1) were used to obtain the converged results.

The measured data of outer surface hemispherical shell was used in 3-D coordinates and recalled through a commercial CAD software package. Subsequently, the developed shell geometry was imported into Abaqus. In addition, thickness variation for each mapped coordinates was inserted as the actual shell thickness. The residual welding stress assumption that was assessed in previous benchmark analyses was used. All of the finite element models were fully clamped, the same as in earlier analyses. For all numerical models, a uniform pressure increment of 1.0 MPa was applied externally as described in Figure 12. The collapse pressures were determined on the maximum load proportional factor that is equal to the critical pressure of the nonlinear buckling analyses. Table 7 presents the comparison of the predicted collapse pressure and the failure shape. In all analyses, the failure modes appear to have a plastic deformation similar to the test results. The modelling of the uncertainty factor of the accuracy, $X_{m}$, was taken as the ratio of experimental and predicted collapse pressure. The mean that was obtained and the COV show a reliable solution with good accuracy, as much as 0.99 and $6.87 \%$. Overall, the qualitative and quantitative validation from the numerical results shows good agreement and can be used for the prediction of the ultimate strength of the actual fabricated structures.

\section{Ultimate Strength Formulation}

The following sections present the analytical quantities used for the pressure hull design codes. The contemporary pressure hull design codes such as PD 5500 (PD 5500 2003), Germanischer Lloyd (DNV-GL 2015), American Bureau of Shipping (ABS 2011) and Det Norske Veritas (DNV 1995) have been chosen to provide a thorough substantiation of the ultimate strength prediction. Most design codes use a conventional deterministic working stress approach, undertaking an analysis for each mode of failure. A single safety factor or several partial safety factors (PSFs), accounting for uncertainties in the loading, fabrication and strength of the pressure hull, were applied to the characteristic strength to determine the allowable working pressure.

The critical buckling $\left(P_{e}\right)$ formulation of a complete spherical shell under external uniform pressure was at first solved by Zoelly in Eq. (1). This classical theory was the basis of the recent design codes. In this further subsection, several design codes will be assessed with the available data from previous and present test results.

\subsection{Det Norske Veritas}

Buckling of an unstiffened spherical shell occurs when the largest compressive principal membrane stress reaches a critical value, $\sigma_{\mathrm{cr}}$. It may be taken as:

$$
\begin{aligned}
& \sigma_{c r}=\sigma_{Y} /\left(\sqrt{1+\lambda^{4}}\right) \\
& \lambda=\sqrt{\sigma_{y} /(0.606 \rho E t / R)} ; \quad \rho=0.5 / \sqrt{1+\frac{R}{100 t}}
\end{aligned}
$$

where $R$ is the shell radius, $t$ is the thickness, $\sigma_{Y}$ is the yield strength of the material, $\lambda$ is the reduced slenderness, and $\rho$ is the imperfection factor. Hence, the collapse pressure $\left(P_{c 1}\right)$ is given by:

$P_{c 1}=2 t \sigma_{c r} / R$
Table 6 Nonlinear FEA benchmark accuracy using fabricated test models

\begin{tabular}{lllll}
\hline Collapse pressure (MPa) & Model 1 $^{\mathbf{O})}$ & Model 3 $^{\mathbf{X})}$ & Model 16 $^{\mathbf{O})}$ & Model 14 $^{\mathbf{X}}$ \\
\cline { 2 - 5 } & $R / t=97$ & $\delta / t=0.5$ & $R / t=78$ & $\delta / t=0.5$ \\
\hline$P_{C, \text { Test }}$ & 10.00 & 9.30 & 10.70 & 10.54 \\
$P_{C, \text { Num }}$ & 9.86 & 9.59 & 11.03 & 10.11 \\
$P_{C, \text { Test }} / P_{C, \text { Num }}$ & 1.01 & 0.97 & 0.97 & 1.04 \\
& $96.39 \%$ Accuracy & & & \\
\hline
\end{tabular}

Notes: O) Stress-relieved model, X) As-welded model 

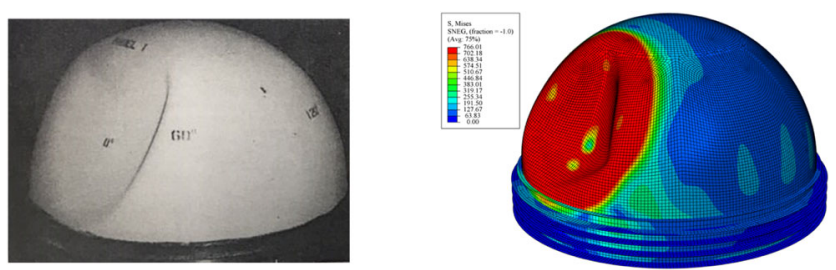

(a) Stress relieved hemisphere (Model No. 1)
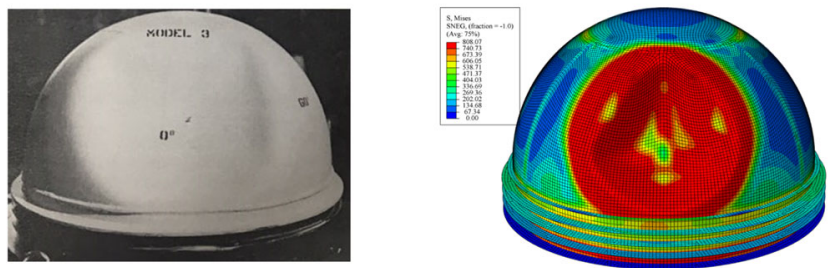

(b) As-welded hemisphere (Model No. 3)

Figure 14 Failure mode validation for the numerical analyses using fabricated model

For a complete sphere subjected to uniform external pressure, the design pressure defined by $P_{Y}$

$P_{Y}=2 \sigma_{Y} t / R$

From the Eq. (2), it shows that value of critical stress, $\sigma_{c r}$, is taking into account the nonlinearity effect of geometry and material. Here, the corresponding safety factor is determined by the value of $P_{Y} / P_{c 1}$ or $\sigma_{c r} / \sigma_{Y}$.

\subsection{American Bureau of Shipping}

In the $\mathrm{ABS}$ code, the limit pressure $\left(P_{c 2}\right)$ for spherical shells is to be obtained from the following equation:

$$
\begin{array}{ll}
P_{c 2}=0.7391 P_{y}\left[1+\left(P_{y} / 0.3 P_{e}\right)^{2}\right]^{-\frac{1}{2}} & \text { for }\left(P_{e} / P_{y}\right)>1 \\
P_{c 2}=0.2124 P_{e} & \text { for }\left(P_{e} / P_{y}\right) \leq 1
\end{array}
$$

where $P_{e}$ and $P_{y}$ shall be determined as Eqs. (1) and (4), respectively.

In determining the allowable working pressure, the limit pressure, $P_{c 2}$ shall be multiplied by the safety factor which is to be taken as 0.67 .

\subsection{PD 5500}

In PD 5500, the collapse pressure is determined based on the ratio between elastic buckling pressure $\left(P_{e}\right)$ to the yield pressure $\left(P_{Y}\right)$ from the Eqs. (1) and (4). The relation is determined by the following equation:

$$
\left(\frac{1}{P_{C 3}}\right)^{2}=\left(\frac{1}{0.3 P_{e}}\right)^{2}+\left(\frac{1}{P_{y}}\right)^{2}
$$

The quadratic form is related to the mean strength curve of the collection of the test model. An acceptable design pressure is controlled by the safety factor which fitted to test data. For the case, of mean strength curve $\left(P_{C 3}\right)$, PD 5500 adopts a guaranteed factor of safety of 1.75 .

\subsection{Germanischer Lloyd}

In this design code, the strength prediction is calculated using the yield pressure and the elastic buckling load. The calculated pressure $\left(\boldsymbol{P}_{\boldsymbol{c} 4}\right)$ is typically associated with Collapse Diving Pressure (CDP), where the safety factor was incorporated through this value. The design or Nominal Diving Pressure (NDP) is approximately half of the CDP. However, the Test Diving Pressure (TDP) should be proofed during the trial where the value is approximately $60 \%$ of the CDP. Interestingly, the prediction of the welded spherical shell can be calculated following the fabrication criteria. The first refers to the spherical ends that are not stress-relieved and the other refers to tempered-stress-relieved spherical ends.

As-welded hemispherical model

$$
\begin{array}{ll}
\text { for } x \leq 0.47 ; & P_{c 4}=P_{e 1} \\
\text { for } 0.47<x \leq 3.18 ; & P_{c 4}=P_{y}\left(0.38+0.195 \frac{P_{e 1}}{P_{y}}\right) \\
\text { for } x>3.18 ; & P_{c 4}=P_{y}
\end{array}
$$

For stress relieved

$$
\begin{array}{ll}
\text { for } x \leq 0.595 ; & P_{c 4}=P_{e 1} \\
\text { for } 0.595<x \leq 2.7 ; & P_{c 4}=P_{y}\left(0.475+0.195 \frac{P_{e 1}}{P_{y}}\right) \\
\text { for } x>2.7 ; & P_{c 4}=P_{y}
\end{array}
$$

where $\boldsymbol{x}$ equal to $\boldsymbol{P}_{\boldsymbol{e} \mathbf{1}} / \boldsymbol{P}_{\boldsymbol{Y}}, \boldsymbol{P}_{\boldsymbol{e} \mathbf{1}}$ is the modified version of Zoelly [1] which expressed as

$$
P_{e 1}=\frac{1.4 E}{\sqrt{3\left(1-v^{2}\right)}}\left(\frac{t}{R}\right)^{2}
$$

\subsection{Strength Formulation Based on the Derived Knockdown Factor}

It is mentioned in the beginning that the gap between theoretical and experimental can be fitted. For this purpose, the analytical buckling formula from Zoelly (Eq. (1)) is defined as the basis. NASA (1969) substantiated the test data and derived the knockdown factor which suited for the shallow and deep spherical shell. Evkin 
Figure 15 Failure mode of the stress relieved (no. 16) and aswelded model (no.14)
Model No. 16

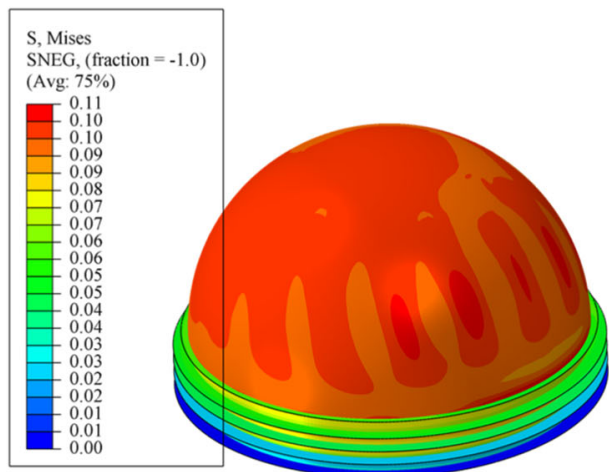

Model No. 14

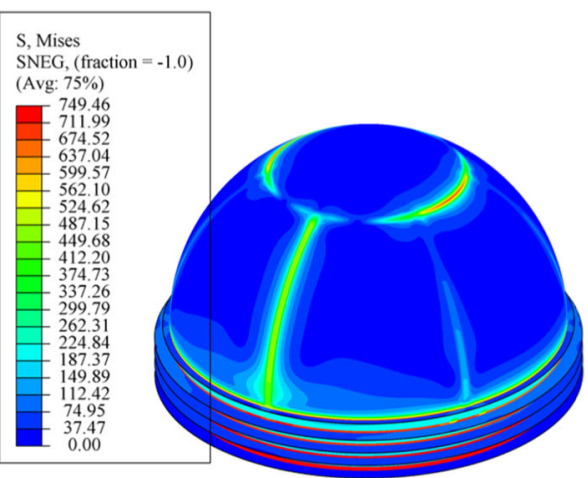

(a) Initial state of the load
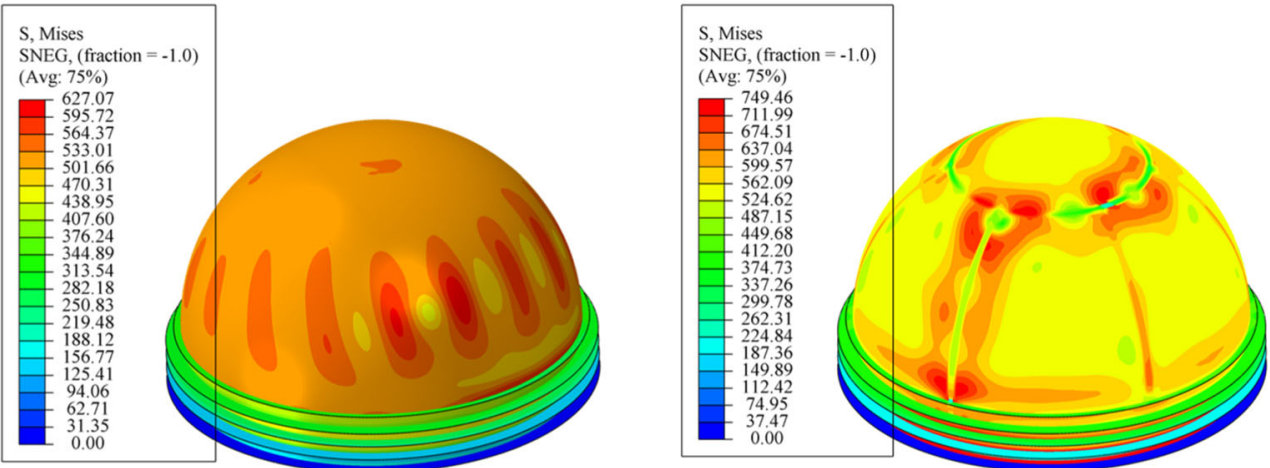

(b) Before reaching the ultimate state
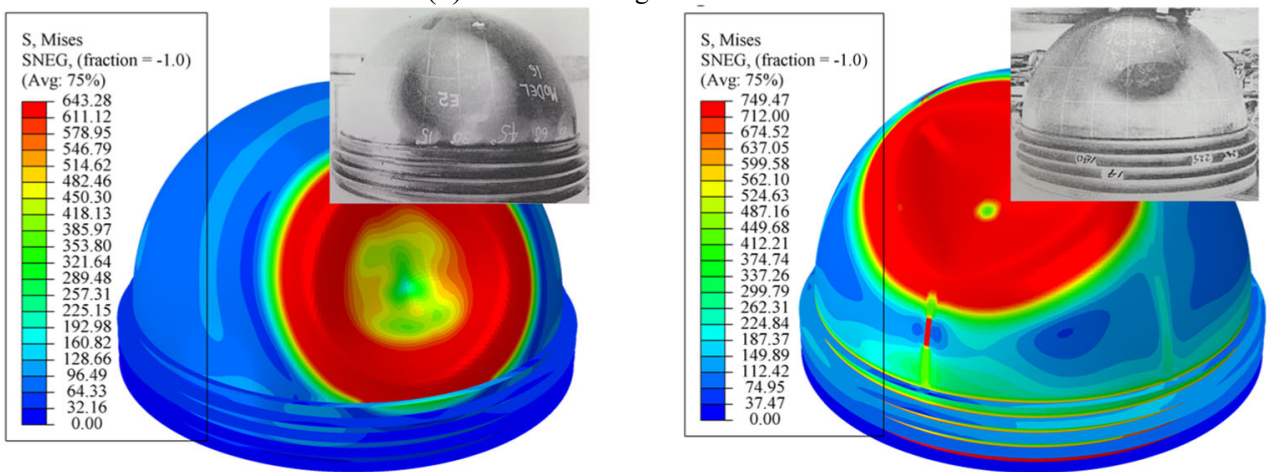

(c) After reaching the ultimate state

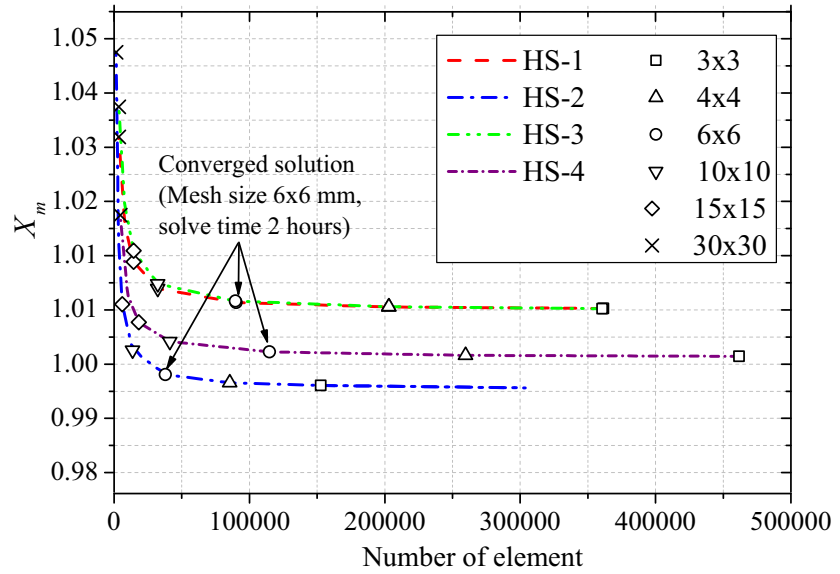

and Lykhachova (2017) and Wagner et al. (2018) later improved the design criterion by taking into account the perturbation effect and expanded the factor for different shell geometries, respectively. The predictions are as follows:

$\bar{\lambda}=1.414\left[12\left(1-\nu^{2}\right)\right]^{1 / 4} \cdot(R / t)^{1 / 2}$, shape parameter for hemisphere $(10)$

$P_{\mathrm{NASA}}=P_{e} \cdot\left(0.14+3.2 / \lambda^{2}\right)$, for $\lambda>2$

$P_{\text {Evkin }}=P_{e} .0 .693 /(1-\nu)^{1 / 5} \lambda^{2 / 5}$, for $\lambda \geq 5$

$P_{\text {Wagner }}=P_{e} \cdot\left(5.172 \lambda^{-1.464}+0.1296\right)$, for $\lambda \geq 5.5$

Figure 16 Mesh strategies for present test model 
Table 7 Deformed shape configurations and calculated collapse prediction

\begin{tabular}{|c|c|c|c|}
\hline Model name & Failure area & Experiment results & Numerical results \\
\hline \multirow[t]{2}{*}{ HS-1 } & Crown & & \\
\hline & & $P_{C}=5.49 \mathrm{MPa}$ & $5.52 \mathrm{MPa}$ \\
\hline \multirow[t]{2}{*}{ HS-2 } & Crown & & \\
\hline & & $P_{c}=9.81 \mathrm{MPa}$ & $P_{c}$ \\
\hline \multirow[t]{2}{*}{ HS-3 } & Shell segment & & \\
\hline & & $P_{C}=3.10 \mathrm{MPa}$ & $P_{C}=3.04 \mathrm{MPa}$ \\
\hline \multirow[t]{2}{*}{ HS-4 } & Shell segment & & \\
\hline & & $P_{c}=4.30 \mathrm{MPa}$ & $P_{C}=4.68 \mathrm{MPa}$ \\
\hline
\end{tabular}

Notes: $X_{m}=P_{c, \text { Exp }} / P_{c . \text { Num }} ;$ Mean $=1.00$, std.Dev $=0.06, \mathrm{COV}=5.97 \%$ 


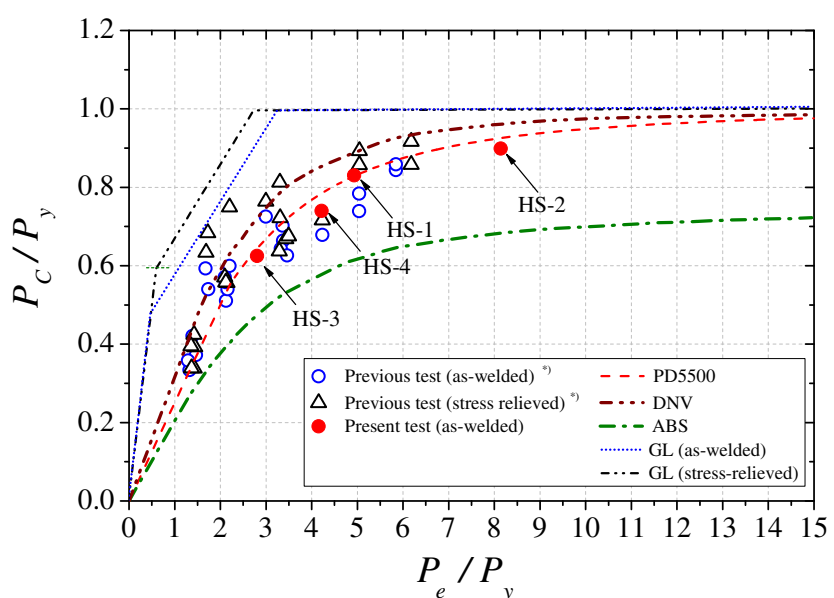

Figure 17 Plot of design equation prediction curve among the test data: *) as-welded and stress-relieved fabricated hemisphere test data obtained from (Kiernan and Nishida 1966; Costello and Nishida 1967; Costello 1970)

It should be noted that the solution of this buckling pressure is based on the shell parameter and empirical knockdown factor, where it was limited to certain population data. However, this formula will be also applied to the previous and recent tested data and discussed in further section.

\section{Discussion}

In Figure 17, the results for prediction above design code are summarized. The prediction was empirically fitted to the experimental data. The biases and coefficient of variation depend on the simplified curve fit of the predicted collapse pressure against the actual pressure. For instance, PD 5500 uses the mean curve instead of the lower bound from ABS. As presented in Table 8 , the lower bound and mean curve result in the average of 1.16 and 1.03 from computed design codes ABS and PD5500, respectively. In case for the GL design equation, two criteria for the fabrication model are presented. The differentiation between welded and stress relief seems to overestimate the prediction by $4 \%$ for the stressrelieved model and $19 \%$ for the as-welded model. As evidenced by the table, the buckling prediction using the estimation from Eqs. (11-13) seems unsatisfied against the hemisphere test data where the COV are more than $30 \%$. These scatters are mainly influenced by the knockdown factor which are most of the knockdown factor in this case were formed by the spherical type.

The detailed comparison of predicted collapse among the nonlinear FE analysis results, design code and the present four test models is tabulated in Table 9. Among the design code formulae, the results of the ABS rules were determined as a lower bound prediction. In contrast, the overestimated results from DNV-GL and GL elucidated the upper-bound prediction; the results showed that the results from PD 5500 are closer to the mean value. Evidently, the numerical investigation not only predicted the failure shape, but the collapse prediction also appeared closer to unity. However, the variation approaches $5.27 \%$, attributed to the residual welding stress needing to be accurately assessed. Overall, the nonlinear FEA results yielded reasonable predictions.

In numerous practical applications of the submarine pressure hull, the hemisphere was constructed mainly of

Table 8 Comparison of design equation against previous test data

\begin{tabular}{lllllll}
\hline Number of tested data & $\begin{array}{l}\text { DNV-GL } \\
\text { (Eqs. 7, 8) }\end{array}$ & $\begin{array}{l}\text { DNV } \\
\text { (Eq. 3) }\end{array}$ & $\begin{array}{l}\text { ABS } \\
\text { (Eq. 5) }\end{array}$ & $\begin{array}{l}\text { PD 5500 } \\
\text { (Eq. 6) }\end{array}$ & $\begin{array}{l}\mathrm{P}_{\text {NASA }} \\
\text { (Eq. 11) }\end{array}$ & $\begin{array}{l}\mathrm{P}_{\text {Evkin }} \\
\text { (Eq. 12) }\end{array}$ \\
\hline Accuracy (mean/COV) & $\begin{array}{l}\mathrm{P}_{\text {Wagner }} \\
\text { (Eq. 13) }\end{array}$ \\
22 as-fabricated & $\begin{array}{l}0.81 / 16 \% \\
\text { stress-relieved }\end{array}$ & $\begin{array}{l}0.96 / 14 \% \\
-\end{array}$ & $\begin{array}{l}1.30 / 10 \% \\
-\end{array}$ & $\begin{array}{l}1.00 / 10 \% \\
-\end{array}$ & $1.47 / 31 \%$ & $1.02 / 35 \%$ \\
\hline
\end{tabular}

Table 9 Comparison of the test and prediction results

\begin{tabular}{|c|c|c|c|c|c|c|c|c|c|c|c|}
\hline \multirow[t]{2}{*}{ Model } & \multirow[t]{2}{*}{$R / t$} & \multirow[t]{2}{*}{$\lambda$} & \multirow{2}{*}{$\frac{P_{c . \text { Exp }}}{(\mathrm{MPa})}$} & \multirow[t]{2}{*}{$P_{c . \mathrm{Num}}$} & \multirow[t]{2}{*}{$P_{e}$} & \multirow[t]{2}{*}{$P_{y}$} & \multicolumn{5}{|c|}{ Experimental / Prediction } \\
\hline & & & & & & & Num & DNV & ABS & PD 5500 & GL \\
\hline HS-1 & 87.46 & 20.94 & 5.49 & 5.52 & 32.59 & 6.61 & 0.99 & 0.95 & 1.36 & 1.00 & 0.83 \\
\hline HS-2 & 52.95 & 16.30 & 9.81 & 9.25 & 88.89 & 10.92 & 1.06 & 0.94 & 1.31 & 0.97 & 0.90 \\
\hline HS-3 & 133.84 & 22.54 & 3.10 & 3.04 & 13.91 & 4.96 & 1.02 & 0.92 & 1.31 & 0.97 & 0.83 \\
\hline \multirow[t]{3}{*}{ HS-4 } & 100.86 & 22.17 & 4.30 & 4.68 & 24.51 & 5.81 & 0.92 & 0.89 & 1.28 & 0.94 & 0.84 \\
\hline & & & & & Mean & & 1.00 & 0.93 & 1.31 & 0.97 & 0.85 \\
\hline & & & & & $\operatorname{COV}(\%)$ & & 5.97 & 2.77 & 2.51 & 2.51 & 3.87 \\
\hline
\end{tabular}




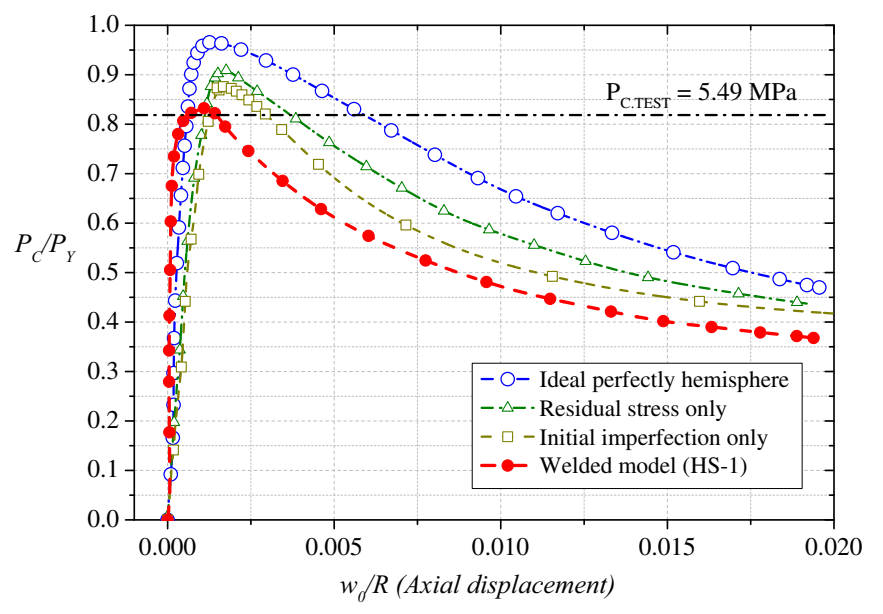

(a) Typical pressure-deflection curves for the hemisphere test model (model HS-1)

Figure 18 Imperfection effect of the steel welded hemisphere.

pre-formed shell segments. Currently, the application of hot forming to pre-form the shell segments is improving, and the initial shapes of imperfections are becoming smaller. Eventually, the detrimental effect of the stress localized from welding is suspected to highly influence the collapse strength. In Figure 18, a parametric dependence of initial imperfection and residual stress on the ultimate strength were investigated numerically. The residual stresses show the stresses induced at the shell welding junction, whereas the initial imperfection is the combination of out-of-roundness and shell thickness variation. The assumed perfect model must have the maximum collapse pressure, i.e. when there is no nonlinear effect induced in the model. The ideal perfectly modelled collapse pressure is approximately 33\% higher than the test result. The residual stress shows reduction in the range of 6 to $15 \%$ from the ideal, where the combined initial imperfection and uneven thickness reduce the collapse strength as much as $18 \%$.

\section{Conclusions}

In this paper, a detailed ultimate strength assessment of the steel-welded hemispherical shell has been carried out. Experimental studies on four fabricated shell segments and a spherical crown have been carried out as the benchmark to substantiate the numerical investigation and design formula assessments. The experimental collapse pressures ranged from 3.10 to $9.81 \mathrm{MPa}$. The most notable points resulting from this study are summarized as follows:

1) From the present test data and remarkable previous experiments, two typical failure modes of the test

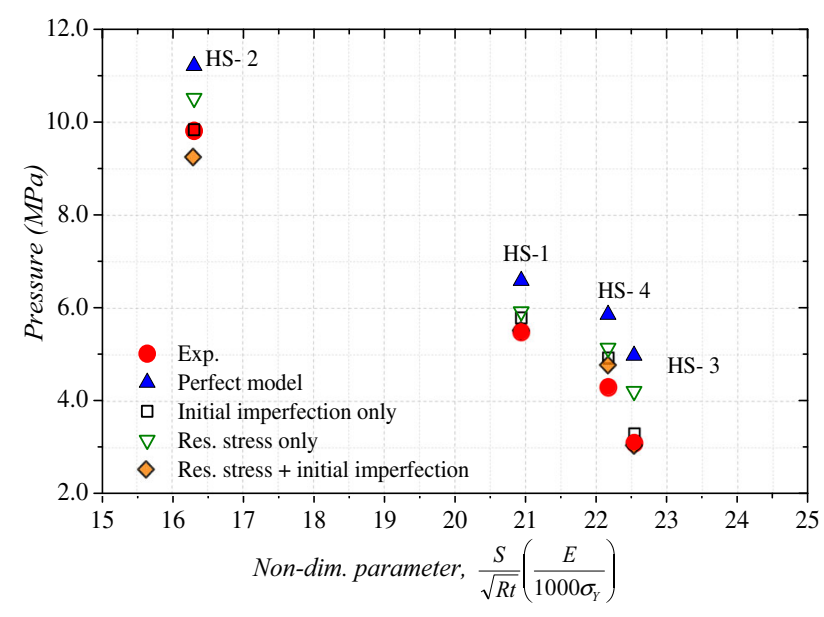

(b) Reduction on the ultimate strength

hemispheres were observed. Two hemisphere models (HS-1 and HS-2) failed at the crown area, while the other two (models HS-3 and HS-4) collapsed at the shellsegment side. For the machined model (near perfect hemisphere), the failure occurred only at the crown. This differentiation was revealed by the effect of imperfection and the residual stress from the fabricated model.

2) In the numerical predictions, the nonlinear FEA was shown to agree well with the experimental results. The predicted failure modes exhibited the same behaviour that was obtained in the experimental results. The predicted collapse pressures varied from 3.04 to $9.25 \mathrm{MPa}$, where the $\mathrm{COV}$ (coefficient of variation) was $6 \%$. From this accurate correlation of the numerical and the experimental results, an assessment of the ultimate strength of the actual structure of the submarine pressure hull can be confidently evaluated.

3) Overall, the prediction of four test hemispheres obtained by the design code (DNV, ABS, PD5500, GL) was in agreement with the corresponding test results with an accuracy of $97 \%$. From the previous collected published test data of 45 models, the accuracy was approximately $85 \%$. The empirical knockdown factor which derived from spherical shell shows inconsistencies when being asses to hemisphere. The improvement of the design formula considering the reduction factor to account for the effect of the residual welding stress and stress-relieving treatment would need to be reevaluated. The detailed investigation of the quantity and shape of the weld lines of the identical size model to the buckling behaviour of the fabricated steel hemisphere is also worthy of further study. 
Acknowledgements The corresponding author would like to acknowledge the Research Grant of Pukyong National University (2019).

Open Access This article is licensed under a Creative Commons Attribution 4.0 International License, which permits use, sharing, adaptation, distribution and reproduction in any medium or format, as long as you give appropriate credit to the original author(s) and the source, provide a link to the Creative Commons licence, and indicate if changes were made. The images or other third party material in this article are included in the article's Creative Commons licence, unless indicated otherwise in a credit line to the material. If material is not included in the article's Creative Commons licence and your intended use is not permitted by statutory regulation or exceeds the permitted use, you will need to obtain permission directly from the copyright holder. To view a copy of this licence, visit http://creativecommons.org/licenses/by/4.0/.

\section{References}

ABS, American Bureau of Shipping (2011) Rules for building and classing underwater vehicles, systems and hyperbaric facilities. American Bureau of Shipping, USA

Błachut J (1998) Buckling of sharp knuckle torispheres under external pressure. Thin-Walled Struct 30:55-77. https://doi.org/10.1016/ S0263-8231(97)00032-3

Błachut J (2014) Experimental perspective on the buckling of pressure vessel components. Appl Mech Rev 66:30-33. https://doi.org/10. $1115 / 1.4026067$

Blachut J (2015) Locally flattened or dented domes under external pressure. Thin-Walled Struct 97:44-52. https://doi.org/10.1016/j.tws. 2015.08.022

Błachut J, Galletly GD (1993) Influence of local imperfections on the collapse strength of domed end closures. Proc Inst Mech Eng Part C J Mech Eng Sci 207:197-207. https://doi.org/10.1243/PIME PROC $1993207 \quad 11702$

Błachut J, Galletly GD (1995) Buckling strength of imperfect steel hemispheres. Thin-Walled Struct 23:1-20. https://doi.org/10.1016/02638231(95)00001-T

Blachut J, Galletly GD, Moffat DG (1991) An experimental and numerical study into the collapse strength of steel domes, in 'buckling of shell structures, on land, in the sea and in the air, (ed.) J.F. Jullien. Elsevier Applied Science Publishers. pp 344-358 (ISBN 1-85166716-4)

Blachut J, Galletly GD, Moreton DN (1990) Buckling of near-perfect steel torispherical and hemispherical shells subjected to external pressure. AIAA 28:1971-1975. https://doi.org/10.2514/3.10506

Błachut J, Jaiswal OR (1999) On the choice of initial geometric imperfections in externally pressurized shells. J Press Vessel Technol Trans ASME 121:71-76. https://doi.org/10.1115/1.2883670

Chen Y, Zhang J, Tang W, Cui W, Zhang M, Wang F (2017) Buckling of bi-segment spherical shells under hydrostatic external pressure. Thin-Walled Struct 120:1-8. https://doi.org/10.1016/j.tws.2017.08. 017

Cho S-R, Muttaqie T, Do QT, Kim SH, Kim SM, Han DH (2018) Experimental investigations on the failure modes of ring-stiffened cylinders under external hydrostatic pressure. Int J Nav Archit Ocean Eng 10:711-729. https://doi.org/10.1016/j.ijnaoe.2017.12. 002

Cho S-R, Muttaqie T, Do QT, Park SH, Kim SM, So HY, Sohn JM (2019) Experimental study on ultimate strength of steel-welded ring-stiffened conical shell under external hydrostatic pressure.
Mar Struct 67:102634. https://doi.org/10.1016/j.marstruc.2019. 102634

Costello MG (1970) The effect of residual stresses on the buckling strength of fabricated HY-80 steel hemispherical shell. Naval ship Research and Development Center. Report 340. USA

Costello MG, Nishida K (1967) The inelastic buckling strength of fabricated HY 80 Steel hemispherical shell. US Naval Ship Research and Development Center. Report 230. USA

Cui W (2018) An overview of submersible research and development in China. J Mar Sci Appl 17:459-470. https://doi.org/10.1007/s11804018-00062-6

DNV, Veritas DN (1995) Buckling strength analysis. Det Norske Veritas Classification AS, Norway

DNV-GL, Det Norske Veritas - Germanischer Lloyd (2015) Rules for classification naval vessels, part 4 sub-surface ships chapter 1 submarines. DNV GL AS. Norway

Evkin AY, Lykhachova OV (2017) Energy barrier as a criterion for stability estimation of spherical shell under uniform external pressure. Int J Solids Struct 118-119:1339-1351. https://doi.org/10.1016/j. ijsolstr.2017.04.026

Faulkner D (1977) Effects of residual stresses on the ductile strength of plane welded grillages and of ring stiffened cylinders. J Strain Anal Eng Des 12:130-139. https://doi.org/10.1243/03093247V122130

Galletly GD, Blachut J (1991) Buckling design of imperfect welded hemispherical shells subjected to external pressure. J Mech Eng Sci 205:175-188. https://doi.org/10.1243/PIME_PROC_1991_ $205 \quad 108 \quad 02$

Galletly GD, Blachut J, Kruzelecki J (1987) Plastic buckling of imperfect hemispherical shells subjected to external pressure. J Mech Eng Sci 201:153-170. https://doi.org/10.1243/PIME_PROC_1987_201 $103 \quad 02$

Grünitz L (2004) Buckling strength of welded HY-80 spherical shells: a direct approach. Ph. D thesis. Arbeitsbereiche Schiffbau der Technischen Universität Hamburg, Germany

Kendrick SB (1977) Shape imperfections in cylinders and spheres: their importance in design and methods of measurement. J Strain Anal $12: 117-122$

Kiernan TJ, Nishida K (1966) The buckling strength of fabricated HY-80 spherical shells. David Taylor Model Basin. Report 172. USA

Krenzke MA, Kiernan TJ (1965) The effect of initial imperfection on the collapse strength of deep spherical shells. David Taylor Model Basin. Report 175. USA

Kohnen W (2018) MTS manned underwater vehicles 2017-2018 global industry overview. Mar Technol Soc J 52:125-151

Moffat DG, Blachut J, Galletly GD (1992) Collapse of externally pressurised petal-welded torispheres and hemispherical end closures, Proc.- of seventh Intl Conf. On pressure vessel technology ICPVT7. VdTUV. Dusseldorf. Germany 1992:119-137

NASA (1969) Buckling of thin-walled doubly-curved shells. NASA space vehicle design criteria (structure). NASA SP-8032. USA

PD 5500 (2003) Specification for unfired fusion welded pressure vessels. British Standard Institution. UK

Shao WJ, Frieze PA (1989a) Static and dynamic numerical analysis studies of hemispheres and spherical caps. Part I: background and theory. Thin-Walled Struct 8:99-118. https://doi.org/10.1016/02638231(89)90038-4

Shao WJ, Frieze PA (1989b) Static and dynamic numerical analysis studies of hemispheres and spherical caps. Part II: results and strength predictions. Thin-Walled Struct 8:99-118. https://doi.org/10.1016/ 0263-8231(89)90038-4

Shen J, Chen Z (2014) Welding simulation of fillet-welded joint using shell elements with section integration. J Mater Process Technol 214:2529-2536. https://doi.org/10.1016/j.jmatprotec.2014.04.034 
Tekgoz M, Garbatov Y, Guedes Soares C (2015) Ultimate strength assessment of welded stiffened plates. Eng Struct 84(2015):325-339. https://doi.org/10.1016/j.engstruct.2014.12.001

Wagner HNR, Hühne C, Niemann S (2018) Robust knockdown factors for the design of spherical shells under external pressure: Development and validation. Int J Mech Sci 141:58-77. https:// doi.org/10.1016/j.ijmecsci.2018.03.029

Zhang J, Zhu B, Wang F, Tang W, Wang W, Zhang M (2017a) Buckling of prolate egg-shaped domes under hydrostatic external pressure. Thin-Walled Struct 119:296-303. https://doi.org/10.1016/j.tws. 2017.06.022

Zhang M, Hua Z, Tang W, Wang F, Wang S (2017b) Buckling of bisegment spherical shells under hydrostatic external pressure. ThinWalled Struct 120:1-8. https://doi.org/10.1016/j.tws.2017.08.017
Zhang J, Zhang M, Cui W, Tang W, Wang F, Pan B (2018a) Elasticplastic buckling of deep sea spherical pressure hulls. Mar Struct 57: 38-51. https://doi.org/10.1016/j.marstruc.2017.09.007

Zhang J, Hua Z, Tang W, Wang F, Wang S (2018b) Buckling of externally pressurised egg-shaped shells with variable and constant wall thicknesses. Thin-Walled Struct 132:111-119. https://doi.org/10. 1016/j.tws.2018.08.013

Zhang J, Wang Y, Tang W, Zhu Y, Zhao X (2019) Buckling of externally pressurised spherical caps with wall-thickness reduction. ThinWalled Struct 136:129-137. https://doi.org/10.1016/j.tws.2018.12. 005

Zoelly R (1915) Uber ein Knickungsproblem an der Kugelschale. Ph.D Thesis. ETH Zurich. https://oi.org/10.3929/ethz-a-000091951 